Running head: Executive control in older bilinguals

\title{
Language proficiency does not modulate executive control in older
}

\author{
bilinguals \\ Ramesh Kumar Mishra ${ }^{\#, a}$, Manasa Padmanabhunia ${ }^{\text {a }}$ Pratik Bhandari ${ }^{\mathrm{b}}$, \\ Shiji Viswambharan ${ }^{\mathrm{a}}$, \& Seema Gorur Prasad $\#$,a
}

${ }^{\mathrm{a} C e n t r e ~ f o r ~ N e u r a l ~ a n d ~ C o g n i t i v e ~ S c i e n c e s, ~ U n i v e r s i t y ~ o f ~ H y d e r a b a d, ~ I n d i a ~}$

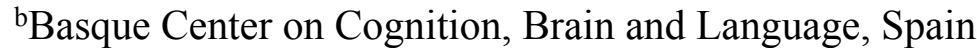

\#Ramesh Kumar Mishra and Seema Gorur Prasad contributed equally to the manuscript.

Correspondence regarding this manuscript should be addressed to:

Ramesh Kumar Mishra, Centre for Neural and Cognitive Sciences, Science Complex,

University of Hyderabad, Hyderabad, Telangana 500046

Ph No: 09451872007

Email id: rkmishra@uohyd.ac.in 


\begin{abstract}
We examined if language proficiency modulates performance in tasks that measure executive control in older Telugu-English bilinguals $(n=50$, Mean age $=57.15$ years $)$. We administered numerical Stroop task, ANT, DCCS task and stop-signal task that are known to tap into different aspects of executive functioning on healthy ageing Telugu-English bilinguals. Second language (English) proficiency was calculated as a cumulative score that considered both subjective and objective measures of L2 fluency and use. Bilinguals were divided into two groups based on the cumulative score and compared on each task. We did not find any effect of language proficiency on any of the executive control measures. The additional Bayesian analysis also supported these findings. Therefore, the results do not support the claim that bilingual language proficiency modulates executive control, at least in the elderly population. We discuss the results with regard to the issue of bilingual advantage in executive control and the role of age and language use.
\end{abstract}

Keywords: older bilinguals, L2 proficiency, executive control, bilingual advantage, healthy ageing 


\section{Introduction}

Whether bilingualism should have any positive effect on one's cognitive and executive control has been controversial lately and remains unsettled (for reviews see Kroll \& Bialystok, 2013; Paap, Johnson, \& Sawi, 2015). Those who have obtained positive correlations between bilingualism and measures of executive functioning have attributed them to different mechanisms such as superior inhibitory control (Green, 1998), attentional disengagement (Mishra, Hilchey, Singh, \& Klein, 2012), monitoring (Costa, Hernández, Costa-Faidella, \& Sebastián-Gallés, 2009), executive processing (Hilchey \& Klein, 2011), and selective attention (Chung-Fat-Yim, Sorge, \& Bialystok, 2017). However, others have found null results in conceptual replications (Anton et al., 2014; Anton, García, Carreiras, \& Duñabeitia, 2016; Paap \& Greenberg, 2013). Apart from the question of which component of executive functions bilingualism should improve, in whom these improvements should be seen is critical. It's intuitive to expect that older people should show benefits of bilingualism more than younger people given their extensive use of and experience with bilingualism. In this study, we examined if such extensive practice with language management over the years makes older bilinguals perform better at executive control tasks. Many studies have shown that bilingualism provides a cognitive reserve that pushes the onset age of degenerative diseases (Alladi et al., 2016, 2017; Bialystok, Anderson, \& Grundy, 2018; Bialystok, Craik, \& Freedman, 2007; Filippi, D'Souza, \& Bright, 2018; Woumans et al., 2015). But, most such reports have relied on hospital records and indirect methods of data acquisition on language use. It is necessary to determine if bilingualism modulates executive control in older, healthy bilinguals even before the onset of these diseases. We examined Telugu-English bilinguals on 
a range of executive control tasks to explore if their second language (L2) proficiency predicts performance on such tasks.

The few studies that have examined bilingual advantage in older bilinguals have obtained conflicting results (See Figure 1 for a summary of some studies). In one of the earliest studies, Bialystok, Craig, Klein, and Viswanatha (2004) found reduced Simon effects in older bilinguals compared to monolinguals. Since then some behavioural and brain imaging evidence have been found for the positive effects of bilingualism on task-switching (e.g., Houtzager, Lowie, Sprenger, \& De Bot, 2017; Gold et al., 2013), inhibitory control (eg., Bialystok et al., 2006, 2008), episodic memory (Schroeder \& Marian, 2012) and selective attention (eg., Soveri et al., 2011) in healthy, older bilinguals. However, not all have observed such positive correlations between bilingualism and executive control in older participants (Anton et al., 2016; Incera \& McLennan, 2017; Ivanova et al., 2016; Papageorgiou et al., 2018; Struys, Duyck, \& Woumans, 2018). For instance, Ivanova et al. (2016) found that older bilinguals are not better in inhibiting intrusions during language switching. Recently, Borsa et al. (2018) compared bilinguals and monolinguals on the Attention Network Task (ANT) in a fMRI study. While they found evidence of a "neural reserve" for bilinguals compared to monolinguals in terms of ACC activation, the two groups did not differ on the behavioural measures.

(Figure 1 about here)

Another strand of research suggests that lifelong bilingualism prevents early onset of neurodegenerative diseases and offers protection against neural tissue loss (Alladi et al., 2013, 
2016, 2017; Bialystok et al., 2007; Woumans et al., 2015). It is assumed that the extensive use of two languages across the lifespan enhances the executive control system which in turn provides a protective cover against such diseases (Abutalebi \& Green, 2016; Bialystok, Poarch, Luo, \& Craik, 2014; Bialystok et al., 2016). But, it is to be noted that several others following a similar methodology of using hospital records have not found any difference in the onset age of dementia between bilinguals and monolinguals (eg., Clare et al., 2016; Lawton, Gasquoine \& Weimer, 2015). For instance, Clare et al. (2016) did not find any significant differences in the age of onset of Alzheimer's disease bilingual older adults compared to the monolinguals. Gollan et al. (2011) found that the age of onset of Alzheimer's disease in Spanish-English bilinguals was later than in monolinguals, but only for the low educated bilinguals.

Bilingualism induced cognitive reserve against diseases is mediated through bilingualism's effect on executive control. Among many casual factors, L2 proficiency seems critical as a proxy for bilingual fluency and competence. L2 proficiency (particularly for the unbalanced, sequential type bilinguals) has been linked to language non-selective activation (Mishra \& Singh, 2016) and also to executive control (Mishra et al., 2012; Singh \& Mishra, 2012, 2013, 2014, 2015). Similar findings have also been reported by other groups (Dong \& Xie, 2014; Festman \& Münte, 2012; Iluz-Chen \& Armon-Lotem, 2014; Tao et al., 2011; Tse \& Altarriba, 2012). Further, brain imaging studies have shown that higher L2 proficiency modulates activation of the Anterior Cingulate Cortex (Abutalebi et al., 2013). Many developmental studies have also shown that an increase in L2 proficiency in children alters brain networks that are critical in conflict resolution, which presumably is also recruited for 
language control in bilinguals (Green, 1998). Luk and Bialystok (2013) have suggested that language proficiency as a continuous measure can be a good variable instead of the traditional comparisons between bilinguals and monolinguals. Considering this, we correlated composite scores on L2 proficiency with executive control measures in older bilinguals.

\section{Current study}

Given this background, where some have found evidence for superior cognitive reserve in older, healthy bilinguals compared to monolinguals, and others have found null results, it is important to seek more cross-cultural data from healthy older bilinguals. The bilinguals in Hyderabad (a large cosmopolitan city in Southern India) live and work in a densely bilingual society. Hyderabad is a metropolitan city with Telugu as its primary language. Telugu is a Dravidian language largely spoken in the states of Telangana and Seemandhra. Telugu has its script which is derived from Brahmi. This script is alphasyllabic or more recently people have termed it "Akshara" (Nag, 2011). In contrast, English is a Roman language and has an alphabetic script. Telugu and English also have different phonological systems and there are no cognates between the languages. English is often spoken as the lingua franca in both work and home environments. We tested a group of Telugu-English bilinguals in Hyderabad on a range of executive control tasks. These bilinguals were fluent in English which they had acquired early in life.

In India, there are English-medium schools that have English as the main medium of education or state-run schools in different provinces where English is only taught as L2. However, all post-school education in India is in English. Therefore, although individuals 
who have studied in English-medium schools tend to have higher fluency in L2, others develop reasonable fluency in L2 when they enter college and university. There are few studies that have directly examined how the medium of instruction at school or college may modulate executive control directly. Our participants were all exposed to English during their college years since all of them had at least completed graduate education. Many were in professions where the demand for English was much higher than other professions. Since these people are older bilinguals, the degree to which English was used at home vs. outside could have differed. There is scant data on the quantum of English used by educated older Indians at home and work. Many writers have indicated that in the last several decades the use of English has grown significantly in India (Mohanty, 2010). In sum, our older bilinguals having studied English either at school or more thoroughly in English medium schools had experience in using both English and Telugu over a long period. Our primary independent variable was language proficiency for which we developed a cumulative score (Ma, Chen, Guo, \& Kroll, 2017). This score gave an overall index of language ability and was developed to treat L2 proficiency as a continuous variable. We reasoned that older bilinguals with better cumulative scores should do better on executive control tasks.

Bilingual advantages have been mostly found across four domains (Bastian \& Gade, 2016; Klein, 2016): an inhibitory control advantage (Green, 1998), an executive processing advantage (Hilchey \& Klein, 2011), advantage in switching or mental flexibility (Bialystok et al., 2012) and more recently an advantage in attentional engagement (Bialystok, 2015). Bilinguals activate both their languages simultaneously and have to routinely deal with competition between these two languages to select the appropriate language. The control 
mechanisms involved in this selection are said to transfer to other nonlinguistic domains as well. But the exact nature of this domain-general control process is still debated. The inhibitory control (IC) model was proposed with the assumption that selecting the appropriate language involves inhibiting the irrelevant language which then enhances inhibitory control in general. However, Hilchey and Klein (2011) argued that in several studies that apparently showed IC advantage, participants were faster on both congruent and incongruent trials which suggests an overall speed advantage and not necessarily only an advantage in inhibition. Subsequently, several studies argued that bilinguals show an advantage on tasks requiring mental flexibility such as switching since they have to routinely switch between two languages (Prior \& MacWhinney, 2010). Most recently, the attentional system has been proposed as the core cognitive system responsible for bilingual advantage (Bialystok, 2017). Attending to two languages since infancy is said to enhance executive attention which then manifests in different tasks. There have been studies in support of all the above models. Thus, it is still not clear exactly which specific aspect of cognitive control is influenced by bilingualism or L2 proficiency.

We chose four tasks that each tap into one or more of the executive functions mentioned above: Attention Network Test (ANT), numerical Stroop task, Dimensional Change Card Sorting task (DCCS) and stop-signal task. The executive processing advantage is commonly observed as an overall RT advantage on a task due to enhanced performance. The attentional advantage was assessed through the ANT task. The task consists of three independent attentional networks: alerting, orienting and executive control network. Participants respond to a central directional arrow on the screen flanked by other arrows on 
either side. A cue (central/spatial/double/no) is presented before the target phase. Bilinguals and monolinguals have shown differences in alerting (Costa et al., 2006), orienting (Poarch \& van Hell, 2012) and conflict effect (Costa et al., 2006, 2009; Tao et al., 2011). Tao et al. (2011) found that early bilinguals (with higher L2 proficiency) showed reduced conflict effect compared to late bilinguals on a modified ANT task. In contrast, Pelham and Abrams (2014) did not observe such differences between early and late adult bilinguals. Anton et al. (2014) also failed to observe an advantage in the ANT task in bilingual children compared to monolingual children.

Numerical Stroop task and stop-signal tasks were used to examine the inhibitory control advantage. Numerical Stroop task is said to tap into the inhibitory control ability of bilinguals. Participants respond to the physical size of a number and ignore the numerical magnitude of the number. While some studies have found that young bilingual adults perform better (larger facilitation and lesser interference) than monolinguals on this task (Hernandez et al., 2010), studies with children and elderly population have sometimes failed to observe such differences (Anton et al., 2016; Dunabeitia et al., 2014). The stop-signal task has been used to measure reactive inhibition in participants. We chose this task to examine whether lifelong bilingualism leads to a benefit in the ability to reactively inhibit. In this task, the participants are required to quickly abort a response when presented with a stop-signal. The evidence for bilingual advantage in this task has been mixed. While Colzato et al. (2008) found no differences between monolinguals and bilinguals in the performance on the stop-signal task, using a similar task Antoniou et al. (2016) found that children speaking two closely related languages have better inhibitory control than monolinguals. The dimensional card sorting 
(DCCS) task was administered to examine the set-shifting ability and mental flexibility in bilinguals. The task involves categorising bivalent stimuli based on either the shape of the object or the colour of the object. Bilinguals have been found to perform better in DCCS task compared to monolinguals indicating that they are better at shifting between two representations (Qu, Low, Zhang, \& Zelazo, 2016; Yang, Hartanto \& Yang, 2017). We divided the participants into high and low proficient based on the L2 cumulative score and compared the performance on all the tasks using both traditional and Bayesian analyses.

\section{Methods}

\section{Participants}

Fifty healthy ageing adults from the city of Hyderabad (34 male, Mean age $=57.2$ years, $S D=4.12$, Age range $=50-65$ years) participated in the experiment (see Table 1 for demographic details). All participants reported normal or corrected-to-normal vision. All participants had Telugu as their L1 (native language). The mean age of acquisition (AoA) of L1 was 1.9 years $(S D=1.2)$ which was calculated based on the self-reported age at which the participants remember first using L1 words in speech. AoA of L2 was 9.46 years $(S D=$ 2.91). All participants provided written consent for their participation. The Institutional Ethics Committee of the University of Hyderabad approved the study.

(Table 1 about here) 
One crucial step in bilingual advantage research is finding an appropriate way to quantify second language proficiency. Researchers have traditionally used either subjective measures such as self-rated proficiency or standardised objective tests such as lexical decision tasks or verbal fluency tasks to assess language proficiency. In a comprehensive analysis of the different factors contributing to bilingualism, Luk and Bialystok (2013) found that bilingual experience was best characterised by a combination of multiple factors - assessed both subjectively and objectively. The authors thus suggest that "a composite of self-rated English proficiency in listening and speaking in conjunction with objective testing is more informative than either method alone" (p. 9). Thus, in this study, participants were divided into high and low L2 proficiency (HP and LP) groups using a median split on L2 proficiency composite score. Many recent studies have used such a composite score to denote bilinguals with different language proficiency (e.g., Ma et al., 2017; McMurray et al., 2010).

L2 proficiency composite score for each participant was calculated by first adding zscores of all the objective L2 proficiency measures (i.e., score on WordORnot vocabulary test, L2 semantic fluency score, and L2 naming latency $\dagger$ in object naming task) and the L2 selfreport score from the questionnaire data, then dividing the sum by square root of sum of variances and covariances of these individual values. Self-assessment has been found to provide a reliable measure of proficiency in bilinguals (Marian, Blumenfeld, \& Kaushanskaya, 2007). Thus, to further validate the accuracy of the composite score, we performed correlation between L2 composite score and L2 self-reported proficiency (averaged over reading, speaking and comprehension). This correlation was found to be significant, $r=0.73, p<0.001$. 
The mean L2 proficiency composite score for HP bilinguals was significantly higher $(M=0.05, S D=0.01, t(36)=8.38, p<0.001)$ in comparison to the LP bilinguals $(M=0.03$, $S D=0.01)$. No such differences were observed for the L1 proficiency composite score, $t(48)$ $=0.65, p=0.52$. The scores on all the control tasks (reported in Table 1) were then compared between the two groups.

\section{Control tasks}

WordORnot. An online vocabulary test (WordORnot, centre for Reading Research, Ghent University) was administered to all the participants as one of the measures of their L2 proficiency. Participants were instructed to judge strings of English letters as a "word" or a "non-word". The total score was the difference between the percentage of correct and incorrect responses. The score for HP bilinguals $(M=54.52 \%, S D=15.48)$ was significantly greater than the score for LP bilinguals $(M=33.44 \%, S D=17.46), t(48)=4.52, p<0.001$

Semantic Fluency Test. We administered semantic fluency tests in both Telugu and English (please Table 1 for the cores). Participants were asked to generate as many names as they could of everyday objects of 4 semantic categories ("birds", "vegetables", "animals", and "fruits") within 1 minute for each category. Language mapping with the categories was counterbalanced across participants. Semantic fluency scores (i.e., the average number of words produced per language per minute) was calculated. The L2 semantic fluency score was significantly higher for HP bilinguals $(M=11.38, S D=2.91)$ compared to LP bilinguals $(M=$ 
7.58, $S D=2.72), t(48)=4.77, p<0.001$. The two groups also differed on L1 semantic fluency score (HP: $M=13.48, S D=3.9, \mathrm{LP}: M=11.4, S D=2.8), t(48)=2.1, p=0.03$.

Language Questionnaire. Participants filled a language background questionnaire that had questions on the native language, languages known, the AoA of L1 and L2, and percentage of time exposed currently to L1, L2, and other language(s) if any. They also provided their L1 and L2 proficiency self-report score for speaking, understanding and reading ability on a scale of 1 to 10,10 being the highest. The average self-reported L2 proficiency was higher for the HP bilinguals compared to the LP bilinguals, $t(48)=4.6, p<$ 0.001. No difference was found in the average self-reported L1 proficiency, $t(48)=0.56, p=$ 0.58. The self-report scores for each category (in both L1 and L2) along with significance values (wherever found) are mentioned in Table 1.

Socio-Economic Status (SES) Questionnaire. Participants were asked to fill in a three-point SES questionnaire where they had to indicate if they belonged to upper, middle or lower socio-economic class. Alongside, they also indicated their monthly income. There was no significant difference, $t(48)=1.12, p=0.27$ in SES of HP bilinguals $(M=2.6, S D=0.5)$ and LP bilinguals $(M=2.44, S D=0.51)$.

Voluntary Object naming. A voluntary object naming task was administered to further obtain an objective measure of proficiency in Telugu and English. The procedure for the selection of black and white line drawings used in the experiment was similar to the one used in the previous studies of Mishra and colleagues (Roychoudhury, Prasad, \& Mishra, 
2016; Bhatia, Prasad, Sake, \& Mishra, 2016). Before the naming task, participants were exposed to the standardised 147 images with their names written both in English and in Telugu. The stimuli in the object naming task were presented using DMDX (Forster \& Forster, 2003) version 5.1.1.3 with DirectX 9.0 on a laptop with 1366 x 768 pixel resolution and $60 \mathrm{~Hz}$ refresh rate. Participants were seated on a chair at a distance of $60 \mathrm{~cm}$ from the monitor. An i-ball M-27 table microphone was used to collect responses. Response latencies were recorded by software DMDX through a voice trigger. A fixation cross appeared at the centre of the screen for $1000 \mathrm{~ms}$ at the beginning of every trial. Then after a blank screen of $250 \mathrm{~ms}$ following the disappearance of the fixation cross, a black-and-white image to be named was displayed for a maximum duration of $2500 \mathrm{~ms}$ or till the participant named the picture. Participants were instructed to name the pictures "in any language that comes to their mind first" as quickly and as accurately as possible. Participants were asked to maintain a balance between the two languages when naming the pictures. We used this method to see if voluntarily these bilinguals are able to choose and name in both the languages.

The audio responses of the object-naming task were recorded by software Audacitywin2.0.5 using which naming errors were manually coded. Object naming latencies on correct trials in L1 and L2 were calculated after discarding trials with latencies less than $150 \mathrm{~ms}$, trials with no or incorrect responses. There was no significant difference in L2 naming latency between HP $(M=1156.82 \mathrm{~ms}, S D=201.95, t(48)=-0.260, p=0.8)$ and LP $(M=1172.39$ $\mathrm{ms}, S D=220.56$ ) bilinguals. Participants did not differ in L1 naming latency as well, $t(48)=$ - 0.9, $p=0.4(\mathrm{HP}: M=1142 \mathrm{~ms}, S D=237, \mathrm{LP}: M=1202 \mathrm{~ms}, S D=229)$. L2 naming latency 
for the two groups was also taken as one of the components for calculation of L2 proficiency composite score.

Ravens Standard Progressive Matrices. Non-verbal IQ was assessed through Ravens Standard Progressive Matrices (Raven, 1958). The task consisted of 60 items divided into 5 types (A to E), each type with 12 items. Each item was a pattern with a missing part and participants had to fill in the missing part from the possible pieces that could fit in the missing part. The order of types and items were arranged in the order of difficulty. Correct answers were counted as IQ score. HP bilinguals $(M=36.04, S D=7.04)$ had higher IQ compared to the LP bilinguals $(M=30.42, S D=7.46), t(48)=2.69, p=0.01$

Mini-Mental State Examination (MMSE). MMSE (Folstein, Folstein, \& McHugh, 1975) was administered to all participants to assess their global cognitive status. MMSE is a test that is widely used by clinicians and researchers to test cognitive function, especially in the elderly population. It is a 30-point questionnaire that examines basic functions under different categories such as recall (“Can you remember the three words you have just said?"), spatial and temporal orientation ("which city are we in?"), ability to follow simple commands ("fold this piece of paper") and so on. Each category carried different points, and the maximum possible score in MMSE was 30. HP bilinguals $(M=28.92, S D=1.53)$ and LP bilinguals $(M=28.72, S D=1.28)$ did not differ in their cognitive status as indicated by the scores on Mini-Mental State Examination, $t(48)=0.5, p=0.62$. 
Visual Digit Span. The digit span task was administered using Inquisit 4.0.0 (2004) which adapted scripts from Woods et al (2011). Five participants (2 HP and 3 LP bilinguals) refused to complete the task. So, it was administered only to 45 participants. In the forward digit span task, there was no significant difference in the number of digits recalled between HP bilinguals ( $n=23, M=6.43, S D=0.95)$ and LP bilinguals $(n=22, M=5.91, S D=1.41)$, $t(43)=1.47, p=0.15$ However, in backward digit span task, the number of digits recalled by HP bilinguals ( $n=23, M=5.87, S D=1.058)$ was more compared to LP bilinguals $(n=22, M$ $=5.18, S D=1.37)$ and this effect was marginally significant, $t(43)=1.89, p=0.07$.

\section{Stimuli and procedure}

\section{Attentional Network Test (ANT)}

Attentional Network Test (Fan et al., 2002; Costa et al., 2008, 2009) was administered to all the participants. Each trial began with a fixation cross at the centre of the screen for 400 ms. Then a cue appeared for $100 \mathrm{~ms}$ followed by a fixation cross for $400 \mathrm{~ms}$. There were four cue conditions: centre cue, double cue, spatial cue (above or below the central fixation) and no-cue. In the centre cue condition, an asterisk appeared at the centre of the screen. In the double cue condition, two asterisks appeared simultaneously 1.06 degree above and below the central fixation cross. In the spatial cue condition, an asterisk appeared 1.06 degree either above or below the central fixation cross. In the no cue condition, no asterisk appeared. In all, except the centre cue condition, fixation cross remained on the screen throughout the cue presentation duration of $100 \mathrm{~ms}$. Following this, a target arrow with flankers was presented for 
$1700 \mathrm{~ms}$ or till the participant made a response. The target stimuli were presented as a set of five horizontal black lines with an arrowhead pointing either right or left on a white background screen. Each line or arrow subtended a visual angle of 0.55 degree, and the distance of separation between two arrows/lines in a set was 0.06 degree. The set of arrows appeared 1.06 degree above or below the central fixation cross. Three different types of target and flanker combinations were used: congruent $(\rightarrow \rightarrow \rightarrow \rightarrow \rightarrow$ or $\longleftarrow \leftarrow \longleftarrow \leftarrow \longleftarrow)$, incongruent $(\leftarrow \leftarrow \rightarrow \leftarrow \leftarrow$ or $\rightarrow \rightarrow \leftarrow \rightarrow \rightarrow)$ or neutral $(--\leftarrow--$ or $--\rightarrow--)$. Participants were instructed to respond to the central arrow. If the central arrow was pointing towards left, they had to press "A" and, if it was pointing towards right, they had to press "L" on the keyboard. Participants were instructed to "try to be as quick and as accurate as possible".

Two within-subjects factors: cue type (central cue, double cue, no cue, spatial cue) and flanker type (congruent, incongruent, neutral) interacted leading to 12 experimental conditions. There was a total of 96 trials (12 experimental conditions repeated eight times). All trials were randomised and presented in one block. There were total 32 congruent trials, 32 incongruent trials, and 32 neutral trials. There was a break for 2 minutes after 48 trials. Twelve practise trials were administered before the experimental trials.

\section{Dimensional Change Card Sort (DCCS) task}

Standard condition of DCCS task (Qu et al., 2013; Wilson et al., 2008) was adopted and administered to all participants. Three cards were simultaneously presented on the computer screen along with a cue word "COLOUR" or "SHAPE". Two target cards were 
presented on the top right and on the top left and a test card was presented on the bottom centre of the screen. The target cards were of different shape and colour (e.g., red star and a blue square). Participants were instructed to match the test card with one of the target cards according to the cue word ("SHAPE" or "COLOUR"). They had to press "A" if the target card on the left side matched with the test card, and press "L" if the target card on the right side matched with the test card. Participants were instructed to "try to be as quick and as accurate as possible".

The task consisted of two blocks: dominant block (non-switch block) and secondary block (switch block). There were 40 trials in the dominant block in which participants had to match target stimuli with the test stimuli by a dominant dimension. There were two types of dominant block: Colour dominant and Shape dominant. The dominant blocks were nonswitch blocks because all the trials within a dominant block were to be matched by the same dimension (colour only, or shape only). The trials in a dominant block are considered baseline trials (discussed in 'Results' section).

In the secondary block, there were total 78 trials -68 dominant trials of dominant dimension and 10 secondary trials of secondary dimension. There were two types of secondary block: one with "Colour" as dominant dimension and "Shape" as a secondary dimension, and the other with "Shape" as dominant dimension and "Colour" as a secondary dimension. If the dominant block was "Colour" then dominant dimension in the secondary block would be "Colour" and secondary dimension would be "Shape". If the dominant block was "Shape" then dominant dimension in the secondary block would be "Shape" and 
secondary dimension would be "Colour". In the secondary block, the dominant trials and secondary trials were randomised across the participants. The secondary block was switch block as participants had to switch in some trials between dimensions (shape and colour).

There were two versions of the DCCS task, one with "Colour" as a dominant dimension (i.e., Colour dominant version), and the other with "Shape" as a dominant dimension (i.e., Shape dominant version). Each participant performed both the two versions of this experiment.

\section{Stop-signal task}

Standard visual two choice stop-signal task (Colzato et al., 2008) with visual go signal and an auditory stop signal was administered to all participants. The interval between two choice signals varied from $1250 \mathrm{~ms}$ to $1750 \mathrm{~ms}$ randomly in steps of $125 \mathrm{~ms}$ (i.e., $1250 \mathrm{~ms}$, $1375 \mathrm{~ms}, 1500 \mathrm{~ms}, 1675 \mathrm{~ms}$ and $1750 \mathrm{~ms}$ ). During this interval, a fixation cross was presented at the centre of the screen. The go signal was an arrow pointing towards right or left, for 2000 ms or till a response was made. Participants were instructed to press " $A$ " on the keyboard if the arrow was pointing towards left and " $\mathrm{L}$ " if the arrow was pointing towards the right. The "stop" signal was a short auditory signal (a beep sound) presented at a short delay after the presentation of the go signal. Participants were instructed to withhold their response in such stop-signal trials. The difficulty of the stop-signal trials was manipulated by varying the stopsignal delay (SSD), i.e., the time between the presentation of go signal and the presentation of the auditory stop signal. 
There were total 110 experimental trials out of which 30\% (i.e., 33 trials) were stopsignal trials and $70 \%$ (i.e., 77 trials) were go trials or choice trials. The SSD was varied systematically in a simple staircase or a tracking method by gradual increase or decrease from the previous SSD by $35 \mathrm{~ms}$. If a previous stop-signal trial was successfully inhibited, then SSD was increased by $35 \mathrm{~ms}$ to increase the difficulty in the next trial, and if the inhibition was not successful, then in the next trial, the SSD was decreased to decrease the difficulty. There were 12 practise trials before the experimental trials.

\section{Numerical Stroop task}

Numerical Stroop task (Anton et al., 2016) was administered to all the participants. Each trial began with a fixation cross at the centre of the screen for $300 \mathrm{~ms}$. Then a pair of digits in Courier New black font appeared on the screen, for $4000 \mathrm{~ms}$ or till the participant made a response. The digits were of two different sizes, font sizes 24 and 48 . There were three different combinations of digit-pair: congruent (when the bigger digit in size had a bigger numerical value), incongruent (when the bigger digit in size had a smaller numerical value) and neutral trial condition (when both the bigger and the smaller digit had the same numerical value). Participants were instructed to respond to the bigger-sized digit in the digit pair, regardless of its numerical value. They had to press " $A$ " on the keyboard if the digit on the left side was bigger and press " $L$ " if the digit on the right side was bigger. For half of the trials, digits on the right side were bigger and for another half, the digits on the left side were bigger. Participants were instructed to try to be "as quick and as accurate as possible". 
Trial types were the within-subjects factor: congruent trials, incongruent trials, and neutral trials. There were total 96 experimental trials created using eight digits $(1,2,3,4,6,7$, 8 and 9). Each digit was presented the same number of times (4 times) in each condition (congruent, incongruent, and neutral) and in total 24 times. There was an equal number of trials in all the three conditions: 32 congruent trials, 32 incongruent trials, and 32 neutral trials. In all the conditions, responses were counterbalanced across the sides: in half of the trials responses were on the right side and in the other half they were on the left side, and trials were randomised across participants. Twelve practise trials were given before the main experiment.

Participants first completed the 4 main cognitive control tests followed by the control tasks and the language questionnaire. The task order was randomized across participants to prevent the effects of fatigue and practice. The experiment was about two hours long. Participants were offered a 10-minute break half-way through the session, if they needed to take rest. All the tasks were administered in a quiet room with no distractions on a Dell Vostro machine with Intel Core i5 processor running Windows 7 connected to a LCD monitor with resolution $1024 * 768$ pixels and refresh rate of $60 \mathrm{~Hz}$. Responses were collected using a Logitech wireless keyboard.

\section{Data analyses and Results}

In each task, trials with RT above and below 2 standard deviations from each participant's mean were excluded as outliers. The resulting data was analysed through 


\begin{abstract}
ANOVA using SPSS (IBM SPSS Statistics for Windows). The specific factors and the dependent variables are mentioned under each task. The descriptive statistics for all the tasks are given in Appendix A. The results are shown in Figure 2. Some researchers have argued that bilingualism must be treated as a continuous variable (Luk \& Bialystok, 2013). Thus, we also performed regression analyses on all the important task measures while treating composite L2 proficiency score as a continuous variable.
\end{abstract}

\title{
Bayesian hypothesis testing and estimation
}

Since we did not find any group difference with traditional analyses, we additionally performed Bayesian analysis because the traditional hypothesis testing only provides evidence to reject a null hypothesis. Researchers have advocated for the additional use of Bayesian statistics along with traditional statistics especially in the case of nonsignificant results (Dienes, 2014). Two methods are primarily used to assess null values using the Bayesian framework: Bayesian hypothesis testing using Bayes factor and Bayesian parameter estimation (Kruschke, 2011). Bayesian hypothesis testing involves setting up two models with two contrasting hypothesis and adjusting the likelihood of each model based on the evidence (data obtained). We tested for model $\mathrm{H}_{0}$ defined as no differences between the two groups against model $\mathrm{H}_{1}$ defined as better performance for HP bilinguals compared to LP bilinguals. We performed independent sample t-tests using JASP comparing both the groups on the key dependent measure in each task. Bayes factors $\left(\mathrm{BF}_{01}\right)$ were computed which quantify the relative evidence for the two competing hypothesis. According to a commonly accepted convention (Jefffreys, 1961; Kruschke, 2011), $3>\mathrm{BF}_{01}>1$ denotes anecodtal evidence, $10>\mathrm{BF}_{01}>3$ denotes moderate evidence and $\mathrm{BF}_{01}>10$ denotes strong evidence for the null hypothesis. Similarly, $1 / 3<\mathrm{BF}_{01}<1$ denotes anecdotal evidence, $1 / 10<\mathrm{BF}_{01}<1 / 3$ 
denotes moderate evidence and $\mathrm{BF}_{01}<1 / 10$ denotes strong evidence for the alternate hypothesis. $\mathrm{BF}_{01}=1$ suggests that the data is inconclusive.

Bayesian parameter estimation for comparing two groups is a method that provides complete information about the posterior distribution (that is, the prior distribution updated by the current data) of the two groups. This estimation method can be used to assess the credibility of differences in means using the HDI and a ROPE (Region of Practical Equivalence) value. Highest density interval (HDI) refers to the $95 \%$ of the most credible values of the posterior distribution. If $95 \%$ of the HDI (for the distribution of the difference in group means) contains zero, then the data is suggestive of a lack of group difference because it indicates that there is not much difference in the individual distributions of each group. A more conservative decision criterion to estimate the likelihood of group differences using the ROPE has also been suggested (Kruschke, 2011). ROPE is a range of values around 0 that is statistically equivalent to the null value. Thus, the ROPE essentially gives the minimum difference in group means that is practically equivalent to no difference between the groups. The ROPE is generally decided based on previous research findings. If $95 \%$ of the HDI falls within the ROPE, then the null effect is accepted. If $95 \%$ of the HDI falls outside the ROPE, then the alternate hypothesis is accepted. The posterior distribution of the difference in group means for each executive control measure along with the ROPE limits was plotted (Figure 2) and analysed using the BEST package in R (Kruschke, Meredith \& Meredith, 2018).

There is no consensus in the literature regarding which of the two Bayesian methods is more appropriate. Both the methods involve different interpretations of the Bayesian inference (Kruschke \& Liddell, 2018). We decided to test our data with both the approaches 
to assess the likelihood of the null effects of L2 proficiency on cognitive control tasks in our sample.

(Figure 2 about here)

(Figure 3 about here)

\section{Attentional Network Test}

Trials in which participants did not respond were excluded from further analyses ( $3.83 \%$ of the total trials). Three participants' data had more than $80 \%$ outliers and were excluded from further analyses. $4.55 \%$ trials in HP group and $4.6 \%$ trials in LP group were discarded as outliers. Incorrect trials $(1.1 \%)$ were also filtered out before analysing the response time data.

We performed separate analyses on each of the attention networks (Executive network, Alerting network and Orienting network). For Executive network analysis, repeated measures ANOVA was conducted on RT with group (HP and LP bilinguals) as a betweensubjects factor and flanker type (congruent, incongruent and neutral) as a within-subjects factor. Similarly, for Alerting network analysis, ANOVA was performed on RT with cue type (no cue, double cue) as within-subjects factor and group (HP and LP bilinguals) as betweensubjects factor. For Orienting network analysis ANOVA was performed on RT with cue type (centre cue and spatial cue) as within-subjects factors and group (HP and LP bilinguals) as between-subjects factor.

Executive Network. Repeated measures ANOVA on executive network showed a significant effect of flanker type, $F(2,44)=168.65, p<0.001, \eta^{2}=0.79$. Participants 
responded faster $(p<0.001)$ on congruent trials $(754.54 \mathrm{~ms})$ compared to incongruent trials (880.95 ms). Responses on neutral trials $(755.7 \mathrm{~ms})$ were also significantly faster $(p<0.001)$ compared to incongruent trials. There was no difference $(p=0.81)$ between congruent RT and neutral RT. There was no main effect of group, $F(2,44)=0.02, p=0.89, \eta^{2}<0.001$. The interactions between flanker type and group also did not reach the level of significance (F $<1)$.

We further explored whether L2 cumulative score modulated conflict effect. Linear regression analysis was used to test if the L2 cumulative score significantly predicted conflict effect. The results of the regression analysis indicated that the L2 cumulative score is not a significant predictor of conflict effect, $r=0.07, F(1,45)=0.26, p=0.61$.

These findings were further confirmed by Bayesian t-test on conflict effect comparing the two groups which resulted in $\mathrm{BF}_{01}=2.79$ suggesting that the null hypothesis was slightly more likely than the alternative one.

Alerting Network. ANOVA on the alerting network showed that the main effect of cue type was significant, $F(1,45)=5.41, p=0.03, \eta^{2}=0.11$. RT on trials with double cue were faster $(792.88 \mathrm{~ms})$ than those with no cue $(805.31 \mathrm{~ms})$. Main effect of group was not observed, $F(1,45)=0.02, p=0.89, \eta^{2}<0.001$. Interaction between flanker type and group was also not significant $(F<1)$. The correlation between alerting effect and L2 proficiency was not found to be significant either, $r=0.07, F(1,45)=0.22, p=0.64$. The lack of group difference was also confirmed by Bayesian t-test on alerting effect $\left(\mathrm{BF}_{01}=2.46\right)$ indicating that the null hypothesis was slightly more likely than the alternative hypothesis. 
Orienting network. ANOVA on orienting network revealed that the main effect of cue type was not significant, $F(1,45)=0.24, p=0.63, \eta^{2}=0.005$. The main effect of group was also absent, $F(1,45)=0.18, p=0.67, \eta^{2}=0.004$, and the interaction between cue type and group was not significant $(F<1)$. Interestingly, linear regression showed a significant positive correlation between orienting effect and L2 proficiency, $r=0.3, F(1,45)=4.43, p$ $=0.04$ indicating that older bilinguals with higher L2 proficiency are better at orienting to cues. Bayesian t-test on orienting effect favoured the null hypothesis $\left(\mathrm{BF}_{01}=5.97\right)$ confirming the lack of group difference on orienting effect.

A ROPE of $20 \mathrm{~ms}$ around 0 was set for all the three effects based on previous studies on bilingual advantage using the ANT (Anton et al., 2014; Costa et al., 2006, 2009). Specifically -20 to $+20 \mathrm{~ms}$ was the range used in Anton et al. (2014) where the authors used a similar estimation method to evaluate the null results. Bayesian estimation method revealed that for alerting effect, $91 \%$ of the HDI was within the ROPE. For orienting and conflict effect, $77 \%$ and $61 \%$ of the HDI was within the ROPE (Figure $3 \mathrm{~A}, 3 \mathrm{~B}$ and $3 \mathrm{C}$ ).

\section{Numerical Stroop task}

Trials in which participants did not respond were excluded ( $0.39 \%$ of total trials). $3.52 \%$ trials in HP group and 3.51\% trials in LP group were excluded as outliers. Incorrect trials $(0.44 \%)$ were also filtered out before further analyses.

We analysed response time data for numerical Stroop task using repeated-measures ANOVA with condition (congruent, incongruent, neutral) as within-subjects factors and group as between-subjects factor. ANOVA on RT showed no significant main effect of condition, $\left.F(2,48)=0.68, p=0.51, \eta^{2}=0.01\right)$ indicating lack of Stroop effect in these 
participants. There was no difference between the RT on congruent (620 ms), incongruent $(624 \mathrm{~ms})$ and neutral trials $(617 \mathrm{~ms})$. Main effect of group was also not observed, $F(1,48)=$ $0.12, p=0.732, \eta^{2}=0.002$. Interaction between condition and group was also not significant $(F<1)$

The lack of Stroop facilitation effect was confirmed by Bayesian t-test comparing RT on congruent trials with $\mathrm{RT}$ on neutral trials (Stroop facilitation) for all participants $\left(\mathrm{BF}_{01}=\right.$ 9.21). RT on neutral trials was also compared with RT on incongruent trials (Stroop interference, $\mathrm{BF}_{01}=1.69$ ) which suggested the absence of Stroop interference effect, although the evidence was not very strong. Bayesian t-test comparing the two groups on Stroop interference effect suggested that null hypothesis was slightly more likely than the alternative one $\left(\mathrm{BF}_{01}=5.54\right)$. We did not perform regression analysis, Bayesian t-test or Bayesian estimation to examine the influence of L2 proficiency on Stroop facilitation/interference as there was no evidence for the basic effects.

\section{Stop-signal task}

We used filtering criteria only for the choice trials before calculating Median RT. Trials in which participants did not respond were excluded from further analyses $(3.3 \%$ of the choice trials). $4.24 \%$ of trials in HP group and $4.15 \%$ trials in LP group were rejected as outliers. Trials with error in discriminating the go signal $(1.5 \%)$ were also filtered out before analysing the RT data. Trials with failed inhibition (responding to stop signal) are generally not excluded from analysis as the dynamic adjustment of the onset of stop signal is designed to generate about 50\% stopping efficiency (Wildenberg et al., 2006). The HP and LP bilinguals were able to stop their responses efficiently on about $85 \%$ of the trials which is 
much higher compared to the stopping rates observed normally. It is possible that the older bilinguals prioritises accuracy over speed thereby successfully inhibiting most responses.

First, we analysed Median RT on choice trials. There was no significant difference $(t=$ $-0.166, p=0.87)$ in median choice RT between HP (978.06 ms) and LP bilinguals (987.28 $\mathrm{ms}$ ). Bayesian t-test also supported this result with a $\mathrm{BF}_{01}=3.13$. Linear regression analysis showed no significant correlation between Median RT and L2 proficiency, $r=0.07, F(1,48)$ $=0.27, p=0.6$. We performed ANOVA on Stop Signal Reaction Time (SSRT) to verify if L2 proficiency could modulate inhibition efficiency. SSRT was calculated by subtracting the mean SSD from the median choice RT. SSRTs were estimated separately for each participant and for each group. The main effect of group was not observed $(t=-0.486, p=0.63)$ which reveals that the LP ( $492.54 \mathrm{~ms}$ ) and HP groups (467.63 ms) did not differ significantly in SSRT.

This result was also confirmed by a Bayesian t-test on SSRT $\left(\mathrm{BF}_{01}=2.4\right)$ and a regression analysis, $r=0.02, F(1,48)=0.01, p=0.91$. A ROPE of $(-40,40)$ was set around 0 to assess group differences in SSRT using the estimation method. There have been very few studies examining cognitive advantage in bilinguals using the stop-signal task and a bilingual advantage has rarely been found with 10 - 20 ms group differences (Colzato et al., 2008; Morales et al., 2013). Thus, we set a slightly larger ROPE of $(-40,40)$ for this measure. The posterior distribution showed that 53\% of the HDI was within the ROPE limits (Figure 3D).

\section{Dimensional Change Card Sort (DCCS) task}

The first four trials in the switch block were removed before the analysis (see Qu et al., 2013 for similar analysis). Incorrect responses and the trials immediately following an 
incorrect response were filtered out $(1.45 \%$ in dominant block and $10.86 \%$ in secondary block in Shape dominant version, and 5.9\% in dominant and $10.7 \%$ in secondary block in Colour dominant version). Further, trials with RT less than $100 \mathrm{~ms}$ and trials with RT above and below 2 standard deviations from each participant's mean were excluded as outliers. Based on this criteria, 3.4\% trials in HP group and 3.5\% trials in LP group were excluded in the dominant block of the Shape dominant version. 2.7\% trials in HP group and $2.6 \%$ trials in LP group were discarded in the secondary block. In the colour dominant version, $3.12 \%$ in the HP group and $3.16 \%$ of trials in the LP group in the dominant block were discarded. $2.46 \%$ trials in HP group and $2.47 \%$ of trials in LP group were discarded in the secondary block.

We compared the participants' performance on the switch trials during the switch (or secondary) blocks with the performance on the baseline trials during the non-switch (dominant) blocks. Local switch cost for RT were calculated by subtracting the median RT on the baseline trials from the median RT on the switch trials during the switch block, then dividing the resultant value by the median RT on the baseline trials. We also calculated global switch cost by subtracting the median RT on the baseline trials from the median RT on the repeat (stay) trials during the switch block then dividing the resultant value by the median RT on the baseline trials (Qu et al., 2013).

We compared the local switch cost and global switch cost in colour task (colour dominant version) and shape task (shape dominant version) separately.

Colour Task. Independent-samples t-test was conducted to compare local switch cost across the two groups. There was no significant difference in local switch cost between LP bilinguals (1.0) and HP bilinguals $(0.85), t(48)=0.27, p=0.79$. There was no significance 
difference in the global switch cost between the LP bilinguals (0.33) and HP bilinguals $(0.31), t(48)=-0.24, p=0.82$. We also did regression analysis on local switch cost and global switch cost with L2 proficiency cumulative score as an independent variable. The results of the regression analysis indicated that the L2 cumulative score is not a significant predictor of either local switch cost $(r=0.09, F(1,48)=0.38, p=0.54)$ or global switch $\operatorname{cost}(r=0.03$, $F(1,48)=0.05, p=0.83)$

Bayesian t-tests on local and global switch costs both provided moderate evidence for the null hypothesis $\left(\mathrm{BF}_{01}=1.27\right.$ and $\mathrm{BF}_{01}=2.96$ respectively $)$. For the estimation method, ROPE was set at $(-0.1,0.1)$ around 0 based on studies that have compared relative switch costs between bilinguals and monolinguals on colour-shape switching task (Prior \& Gollan, 2011). 0.1 is still a conservative estimate because it indicates a $10 \%$ increase in switch cost between the two groups. The posterior distribution showed that $25 \%$ of the HDI was within ROPE for local switch costs and $80 \%$ of the HDI was within ROPE for global switch costs (Figure $3 \mathrm{E}$ and $3 \mathrm{~F}$ ). This suggests that there is some evidence to accept the null hypothesis for global switch costs while there is very little evidence to support the null difference on local switch costs.

Shape Task. There was no significant difference in local switch cost between LP (0.95) and HP bilinguals (0.89), $t(48)=-0.45, p=0.66$ LP $(0.44)$ and HP bilinguals $(0.48)$ did not differ on global switch cost as well, $t(48)=0.40, p=0.69$. Linear regression analysis was used to verify if the L 2 cumulative score significantly predicted switch costs. The results of the regression analysis indicated that the L2 cumulative score is not a significant predictor of local switch cost $(r=0.02, F(1,48)=0.02, p=0.88$.$) , and global switch cost (r=0.04, F$ $(1,48)=0.06, p=0.8)$. 
Bayesian t-tests on local and global switch costs also provided moderate to strong evidence that the null hypothesis was more likely $\left(\mathrm{BF}_{01}=2.48\right.$ and $\mathrm{BF}_{01}=4.6$ respectively). With a similar ROPE value as used for the shape dominant blocks, the estimation method showed that $53 \%$ of the HDI and $68 \%$ of the HDI were within the ROPE for local and global switch costs, respectively (Figure $3 \mathrm{G}$ and $3 \mathrm{H}$ ).

We failed to find any significant effects of L2 proficiency on cognitive control abilities through multiple analyses. To test whether the quantum of engagement with L2 (and not just proficiency in L2) modulates performance on executive control tasks, we performed correlations between percentage of exposure to L2 (self-reported) and the executive control measures (the results are reported in Appendices B - E). We observed that higher exposure to L2 was linked to higher alerting and orienting effect $(r=0.35, p<0.05$ and $r=0.4, p<0.05$ respectively) as well as to lower switch costs in the DCCS task (shape, $r=-0.26, p<0.1$ ). To test this relationship further, we divided the participants into two groups based on exposure to L2 (HE: high exposure, LE: low exposure). We performed an analysis of covariance (ANCOVA) on each executive control measure with exposure as the independent variable and L2 proficiency as the covariate (the group means, and F values are reported in Appendix F). After controlling for L2 proficiency, high exposure group showed a greater orienting effect, $F$ $(1,44)=4, p=0.05, \eta^{2}=0.08$ and lesser Stroop effect, $F(1,47)=6.14, p=0.02, \eta^{2}=0.11$ compared to low exposure group. The percentage of exposure did not have a significant effect on any other measure.

\section{Discussion}


We examined whether L2 proficiency improves cognitive functioning in older bilinguals. We administered a set of tasks measuring various aspects of executive control on older, healthy, Telugu-English bilinguals in the age range of $50-65$ years. The ANT, numerical Stroop task, stop-signal task, and DCCS task were administered to all the participants along with a battery of other tasks to measure L2 proficiency, memory capacity and IQ. Bilinguals were divided into HP and LP based on a composite score derived from various objective and subjective measures of L2 proficiency. The two groups' performance was not found to differ on any of the tasks. The null effects were further confirmed through Bayesian analysis. Based on our study, we conclude that L2 proficiency does not lead to cognitive advantages in well educated, healthy, ageing Telugu-English bilinguals. Although our group has earlier shown that young HP bilinguals (e.g., Singh \& Mishra, 2012, 2013, 2015, 2016) are better than LP bilinguals on executive control tasks, we did not observe this advantage in the older population. These results are in line with a growing number of studies/reviews that have reported null effects of bilingualism on cognitive functioning (e.g., Lehtonen et al., 2018; Paap \& Greenberg, 2013; Saint-Aubin et al., 2018). In a recent metaanalysis of studies done on the protective role of bilingualism in cognitive decline, Mukudam, Sommerlad and Livingston (2017) failed to find consistent evidence for a bilingual advantage in cognitive decline. They argued that retrospective studies on patient records are susceptible to several confounding factors making the findings difficult to interpret. Our study takes care of these confounding factors since we experimentally tested a homogeneous group of bilinguals with similar levels of education and socioeconomic background, differing only in L2 proficiency. 
What could be the reason for this lack of group difference? It is possible that language proficiency can only boost executive control if the bilinguals are practising bilingualism every day. Unlike university students who function within a bilingual setup most of their time, the older bilinguals spend most of the time at home. Self-report data from our participants show that the percentage of exposure to L2 did not differ $(p=0.28)$ between HP $(26.3 \%)$ and LP (20.1\%) participants. The current switching frequency also did not differ $(p=0.61)$ between the two groups. Additionally, the percentage of exposure to L2 was significantly lesser ( $p<$ 0.001) than L1 for both the groups. These measures suggest that although there was a difference in the level of proficiency between the two groups, the exposure to L2 did not differ significantly between the two groups. As a result, such bilinguals may not often use the skills like shifting, switching, inhibition or monitoring. And without the constant practice of these skills through bilingualism, executive control may not be modulated.

In a recent study, Borsa et al. (2018) found evidence for such a link between language use and executive control. On an ANT task, they observed that exposure to L2 was a significant predictor of interference effects. This clearly indicates that the quantum of engagement with L2 influences general executive control. Greater engagement of L2 provides greater opportunity for exercising language control resulting in executive control benefits. To test this hypothesis with our current dataset, we performed Analysis of Co-variance (ANCOVA) with the percentage of exposure to L2 as the independent variable and L2 proficiency as the covariate. This was done to examine whether exposure to L2 modulates cognitive functioning, independent of differences in proficiency. If exposure to L2 (and not L2 proficiency) modulates executive functioning in bilinguals, then we should observe better 
executive control performance in the high exposure group. However, this was not observed in any of the measures except the ANT orienting effect and the Stroop effect. The reduction in Stroop effect is not straightforward to interpret as there was no significant evidence for the existence of the Stroop effect itself. Additionally, the increased orienting effect was only marginally significant. Nevertheless, these results underscore the importance of appropriately quantifying the context of a bilingual and considering it as an independent variable in studies examining cognitive advantage in bilinguals. Further, it is to be noted that we recorded the subjective report of participants' exposure to L2, but not their usage of L2. Although there might be correlations between the two, the assumption is that active usage of the two languages (not just passive exposure to them) requires some of the core cognitive mechanisms such as inhibition, monitoring etc. which then translates into better performance on tasks measuring these components (eg., Yang, Hartanto, \& Yang, 2016).

Another possible reason for the lack of effect of L2 proficiency could be that there is a ceiling effect with respect to bilingual advantage and it is possible that both HP and LP groups might have shown an advantage compared to a monolingual group. For instance, Luo et al. (2010) found that high and low vocabulary bilinguals differed from monolinguals in executive function measures in a letter fluency task, but no difference was found within the two types of bilinguals. This shows that executive control (indexed by performance on the letter fluency task) could depend on the existence of bilingualism but not on the levels of it. We are not in a position to evaluate this since our study did not have a monolingual control group for the reasons mentioned in the introduction section. But it is to be noted that the two groups of bilinguals in Luo et al. (2010) differed in vocabulary size but not in proficiency. A 
lot of research has shown that bilingual language control may be linked to language proficiency. Therefore, in the absence of a monolingual control group, one can expect a difference between groups differentiated by L2 proficiency. In line with this, Luk and Bialystok (2013) note that, bilingualism should not be treated as a categorical variable (in terms of presence vs. absence of bilingualism) and that multiple factors such as language use and proficiency must be taken into consideration while examining bilingualism.

Our data are in contrast to several earlier findings of bilingual advantage in the elderly population (e.g., Bialystok et al., 2006, 2007, 2008). It is to be noted that a vast majority of studies reporting differences in executive control in elderly bilinguals have compared bilinguals with monolinguals (eg., Alladi et al., 2013, 2015; Bialystok et al., 2006, 2007, 2008; Houtzager et al., 2017). This could be problematic because of the difficulty in matching two different groups on a host of other confounding factors. This is particularly true in the Indian context, in a large metropolitan city like Hyderabad, where monolinguals are mostly illiterates/low educated with no additional knowledge of any language. Mishra and colleagues have done many studies on Indian illiterates who were largely monolinguals knowing only their native language (Huettig, Singh, \& Mishra, 2011; Mishra, Singh, Pandey, \& Huettig, 2012; Olivers, Huettig, Singh, \& Mishra, 2014). This could bring serious confounds into the study since the level of education has been shown to play a significant role in modulating bilingual advantage (Gollan et al., 2011). Thus, our data raises questions on studies that have argued for a cognitive reserve in bilinguals based on data from hospital records from a population similar to the one we have used in this study (Alladi et al., 2013, 2015). For instance, Alladi et al. (2013) find the literacy level to be higher in bilinguals compared to 
monolinguals. They "correct" for this effect statistically through a univariate GLM analysis. However, such statistical correction of confounding factors has been criticised (Miller \& Chapman, 2001; Paap, Johnson, \& Sawi, 2014). It is also difficult to determine the extent to which the patients used both the languages when they were healthy based on hospital records or data from caretakers. As a result, it is hard to know whether bilingualism was indeed responsible for the later onset of such neurodegenerative diseases.

It is possible to question whether our data collection methods were sensitive enough to observe any subtle differences, considering the prevalence of null effects in our study. To examine this, we performed correlations between some demographic variables (such as age, gender, IQ), L2 measures (percentage of exposure to L2, L2 proficiency score etc.) and task performance (correlation tables are given in Appendices B - E). We observed that the percentage of exposure to L2 significantly predicted an increase in the scores on IQ and MMSE. Higher scores on MMSE also led to lower switch costs and lower Stroop effects. While there was no consistent pattern to these correlations, it nevertheless provides some evidence that our methods were sensitive enough to detect group differences, if any. Importantly, age did not correlate significantly with any of the executive control measures. This is surprising since cognitive capacities generally decline with age (Craik \& Salthouse, 2011; Douaud et al., 2014). For instance, in a large sample of 484 participants, Douaud et al. (2014) found that age was a significant predictor of cognitive decline. In an analysis of the brain structures of healthy participants ranging from 8 years to 85 years, the authors observed that with old age, brain areas associated with disorders such as Alzheimer's degenerated faster compared to rest of the brain areas. Interestingly, Borsa et al. (2018) also found that age 
correlated significantly with conflict effect (on ANT), but only in monolinguals and not in bilinguals. This was taken as evidence that bilingualism acted as a reserve against the natural age-related cognitive decline. While monolinguals experienced a decline in their cognitive capacities as they aged, the practice of two languages in bilinguals stopped or slowed down such decline. It is possible that this null correlation in our study between age and any of the executive control measures also suggests a positive influence of bilingualism in healthy older bilinguals. We can't be confident of this explanation since we did not have a monolingual group for comparison. However, this perspective of bilingualism as a factor that slows down cognitive decline in healthy older bilinguals is worthy of more serious enquiry.

We confirmed the lack of group differences on the cognitive control measures through multiple analyses methods. In addition to the traditional frequentist statistics, we also performed two different types of Bayesian analysis - a model comparison using Bayes factors and the Bayesian estimation method - to assess the likelihood of the null effect. Bayesian analysis is important in this context because the traditional null hypothesis testing (NHST) does not have provisions for accepting a null hypothesis. The results from both Bayes factors and estimation method failed to show any strong evidence for bilingual advantage. The Bayes factors for all the tasks indicated that there was moderate to strong evidence for accepting the null hypothesis. The parameter estimation method also some provided some support for the null hypothesis. According to this method, the alternative hypothesis can be accepted only if $95 \%$ of the HDI falls outside the ROPE. This was not observed for any of the tasks suggesting that we don't have sufficient evidence in support of the bilingual advantage claim. Importantly, our data is more suggestive of a lack of group difference since the posterior 
distribution of the difference of group means for most of the tasks was centered around zero suggesting a high probability of no difference between the groups. The only exception is the local switch cost on the DCCS task shape-dominant block which indicates a possible group difference. But it may not be a very reliable effect since is not supported by either the Bayes factor analysis or the traditional t-tests. Finally, it can be pointed out that the percentage of HDI within the ROPE for each task was always below 95\% (the null hypothesis can be accepted when at least $95 \%$ of the HDI is within the ROPE) suggesting that maybe there wasn't enough evidence to conclusively accept the null hypothesis based on this method. However, it is to be noted that due to the paucity of experimental research examining the role of L2 proficiency on cognitive control in older bilinguals, specifically in India, it is difficult to decide on how big of an effect counts as a "true" effect. So, the ROPE limits set in this study have to be treated as a rough estimation. Secondly, the Bayesian estimation method, as the name suggests, is meant to be useful for estimating the extent of the difference in group means rather than providing strict criteria for binary decisions on whether an effect is significant or not.

One of the limitations of this study is the small sample size (n). Previous scholarship on Indian ageing bilinguals on this question (eg., Alladi et al., 2013) was based on hospital records and not experimental investigations. Because this was the first experimental study on an ageing population in India, there were several limitations in recruiting a large group of participants. It is true that a very large $\mathrm{n}$ in any experimental investigation induces confidence in the results - positive or negative (Paap, 2014). However, there have been other studies with low sample sizes that have shown a null effect of bilingualism (Anton et al., 2016; Kousaie \& 
Phillips, 2012; Papageorgiou et al., 2018; Ramos et al., 2017). And these findings have been used in other meta-analysis or reviews for claiming the no-advantage position (De Bruin, Treccani, \& Della Sala, 2015; Hilchey \& Klein, 2011; Paap, Johnson \& Sawi, 2015). Further, to address this limitation as best as possible, we performed Bayesian analysis. The null hypothesis significance testing (NHST) is susceptible to false conclusions, especially with small sample sizes. One of the reasons is the dependence of $p$ values on stopping intentions (the decision to stop collecting data). But, this problem is not as severe with the Bayesian method which is considered to be quite robust as "Bayesian inference does not depend on stopping and testing intentions" (Kruschke \& Liddell, 2018). This effectively means that the n at which we stopped collecting data (big or small) should not drastically modify our Bayesian inference. However, it is true that large-scale studies (whenever possible) will be able to throw more light on the links between L2 proficiency and executive control.

Whether knowing more languages leads to higher executive functioning advantage is not clear from available studies (Chertkow, Whitehead, Philips et al. 2010). We are arguing that since older bilinguals may not indulge in many bilingual conversations, they may not find opportunities to switch/inhibit/monitor often. Ours is a performance-based account of neuroplasticity that bilingualism might have bestowed. However, some researchers (e.g., Bak et al., 2014) have argued that quantum of language use may not matter for executive control. Bak et al. (2014) argue that since bilinguals unintentionally activate the two languages and inhibit one for selection, their executive control gets exercised irrespective of language use. It is true that many studies have shown that bilinguals activate two languages in parallel, but we do not know from such studies how the competition between the two languages is resolved. 
Additionally, language proficiency has been shown to influence such non-selective parallel language activation (Singh \& Mishra, 2016). It seems problematic to assume that the overt practice of a skill plays a minor role in inducing plasticity. Unless bilingualism is in use in a societal scenario with actual partners, just the knowledge of two languages and passive activation of them may not be enough to induce neuroplasticity. In line with this argument, many studies have shown that bilinguals who use language more show better performance on executive control tasks (Hartanto \& Yang, 2016).

In conclusion, our study indicates that differences in language proficiency may not be sufficient to induce an advantage in cognitive functioning in healthy, elderly bilinguals. It is the first study to examine the influence of L2 proficiency in Indian bilinguals using an experimental paradigm. However, we are not suggesting that there are no cognitive benefits of bilingualism at all. Rather, it is important to consider the socio-linguistic context of a bilingual population before taking either a null effect or an advantage into serious consideration. Bilingualism is a social phenomenon which cannot be studied in isolation and expected to generalise across different contexts. Future studies examining the role of bilingualism should consider including language use and the overall linguistic context of the bilinguals as a potential factor. Comparing two groups of bilinguals with similar levels of proficiency but differing in the amount of L2 use will provide useful evidence to understand this issue better. For example, one may find a difference between sedentary home-bound older bilinguals who just speak one language at home and other active older bilinguals who use two languages at work. In the Indian context, language use is often differentiated between work and home domains. Future studies with such variables may throw new light on the boundary 
conditions of the phenomenon which is much required to resolve the debate surrounding this issue.

\title{
References
}

\author{
Abutalebi, J., Della Rosa, P. A., Ding, G., Weekes, B., Costa, A., \& Green, D. W. (2013). \\ Language proficiency modulates the engagement of cognitive control areas in \\ multilinguals. Cortex, 49(3), 905-911.
}

Abutalebi, J., \& Green, D. W. (2016). Neuroimaging of language control in bilinguals: neural adaptation and reserve. Bilingualism: Language and cognition, 19(4), 689-698.

\begin{abstract}
Alladi, S., Bak, T. H., Duggirala, V., Surampudi, B., Shailaja, M., Shukla, A. K., ... \& Kaul, S. (2013). Bilingualism delays age at onset of dementia, independent of education and immigration status. Neurology, 81(22), 1938-1944.
\end{abstract}

Alladi, S., Bak, T. H., Mekala, S., Rajan, A., Chaudhuri, J. R., Mioshi, E., ... \& Kaul, S. (2016). Impact of bilingualism on cognitive outcome after stroke. Stroke, 47(1), 258-261.

Antón, E., Duñabeitia, J. A., Estévez, A., Hernández, J. A., Castillo, A., Fuentes, L. J., ... \& Carreiras, M. (2014). Is there a bilingual advantage in the ANT task? Evidence from children. Frontiers in psychology, 5, 398. 
Antón, E., García, Y. F., Carreiras, M., \& Duñabeitia, J. A. (2016). Does bilingualism shape inhibitory control in the elderly?. Journal of Memory and Language, 90, 147-160.

Ardila, A., Pineda, D., \& Rosselli, M. (2000). Correlation between intelligence test scores and executive function measures. Archives of clinical neuropsychology, 15(1), 31-36.

Bak, T. H., Nissan, J. J., Allerhand, M. M., \& Deary, I. J. (2014). Does bilingualism influence cognitive aging?. Annals of neurology, 75(6), 959-963.

Bhatia, D., Prasad, S. G., Sake, K., \& Mishra, R. K. (2017). Task Irrelevant External Cues Can Influence Language Selection in Voluntary Object Naming: Evidence from HindiEnglish Bilinguals. PloS one, 12(1).

Bialystok, E., Craik, F. I., \& Freedman, M. (2007). Bilingualism as a protection against the onset of symptoms of dementia. Neuropsychologia, 45(2), 459-464.

Bialystok, E., Craik, F., \& Luk, G. (2008). Cognitive control and lexical access in younger and older bilinguals. Journal of Experimental Psychology: Learning, memory, and cognition, 34(4), 859.

Bialystok, E., \& Feng, X. (2009). Language proficiency and executive control in proactive interference: Evidence from monolingual and bilingual children and adults. Brain and language, 109(2), 93-100. 


\begin{abstract}
Bialystok, E., Barac, R., Blaye, A., \& Poulin-Dubois, D. (2010). Word mapping and executive functioning in young monolingual and bilingual children. Journal of Cognition and Development, 11(4), 485-508.
\end{abstract}

Bialystok, E., Craik, F. I., \& Luk, G. (2012). Bilingualism: consequences for mind and brain. Trends in cognitive sciences, 16(4), 240-250.

Bialystok, E., Poarch, G., Luo, L., \& Craik, F. I. (2014). Effects of bilingualism and aging on executive function and working memory. Psychology and aging, 29(3), 696.

Bialystok, E. (2015). Bilingualism and the development of executive function: The role of attention. Child Development Perspectives, 9(2), 117-121.

Bialystok, E., Abutalebi, J., Bak, T. H., Burke, D. M., \& Kroll, J. F. (2016). Aging in two languages: Implications for public health. Ageing research reviews, 27, 56-60.

Bialystok, E. (2017). The bilingual adaptation: How minds accommodate experience. Psychological bulletin, 143(3), 233.

Bialystok, E., Anderson, J. A. E., \& Grundy, J. G. (2018). Interpreting cognitive decline in the face of cognitive reserve. Linguistic Approaches to Bilingualism, Online First. Retrieved from https://benjamins.com/catalog/lab.18040.bia 
Chertkow, H., Whitehead, V., Phillips, N., Wolfson, C., Atherton, J., \& Bergman, H. (2010). Multilingualism (but not always bilingualism) delays the onset of Alzheimer disease: evidence from a bilingual community. Alzheimer Disease \& Associated Disorders, 24(2), 118-125.

Chung-Fat-Yim, A., Sorge, G. B., \& Bialystok, E. (2017). The relationship between bilingualism and selective attention in young adults: Evidence from an ambiguous figures task. The Quarterly Journal of Experimental Psychology, 70(3), 366-372.

Colzato, L. S., Bajo, M. T., van den Wildenberg, W., Paolieri, D., Nieuwenhuis, S., La Heij, W., \& Hommel, B. (2008). How does bilingualism improve executive control? A comparison of active and reactive inhibition mechanisms. Journal of Experimental Psychology. Learning, Memory, and Cognition, 34(2), 302-12. https://doi.org/10.1037/0278-7393.34.2.302

Costa, A., Hernández, M., \& Sebastián-Gallés, N. (2008). Bilingualism aids conflict resolution: Evidence from the ANT task. Cognition, 106(1), 59-86.

Costa, A., Hernández, M., Costa-Faidella, J., \& Sebastián-Gallés, N. (2009). On the bilingual advantage in conflict processing: Now you see it, now you don't. Cognition, 113(2), 135-149.

Craik, F. I., \& Salthouse, T. A. (Eds.). (2011). The handbook of aging and cognition. Psychology Press. 
De Bruin, A., Treccani, B., \& Della Sala, S. (2015). Cognitive advantage in bilingualism: An example of publication bias?. Psychological science, 26(1), 99-107.

Dong, Y., \& Xie, Z. (2014). Contributions of second language proficiency and interpreting experience to cognitive control differences among young adult bilinguals. Journal of Cognitive Psychology, 26(5), 506-519.

Douaud, G., Groves, A. R., Tamnes, C. K., Westlye, L. T., Duff, E. P., Engvig, A., ... \& Matthews, P. M. (2014). A common brain network links development, aging, and vulnerability to disease. Proceedings of the National Academy of Sciences, 111(49), 1764817653.

Draine, S. C. (2004). Inquisit 2.0. 50401 [Computer software]. Seattle, WA: Millisecond Software

Fan, J., McCandliss, B. D., Sommer, T., Raz, A., \& Posner, M. I. (2002). Testing the Efficiency and Independence of Attentional Networks. Journal of Cognitive Neuroscience, $14(3), 340-7$.

Festman, J., \& Münte, T. F. (2012). Cognitive control in Russian-German bilinguals. Frontiers in Psychology, 3, 115. 
Filippi, R., D’Souza, D., \& Bright, P. (2018). A developmental approach to bilingual research: The effects of multi-language experience from early infancy to old age. International Journal of Bilingualism, Online First. Retrieved from https://journals.sagepub.com/doi/abs/10.1177/1367006917749061

Folstein, M. F., Folstein, S. E., \& McHugh, P. R. (1975). “Mini-mental state”: A practical method for grading the cognitive state of patients for the clinician. Journal of Psychiatric Research, 12(3), 189-198.

Forster, K. I., \& Forster, J. C. (2003). DMDX: A windows display program with millisecond accuracy. Behavior Research Methods, Instruments, \& Computers, 35, 116-124.

Friedman, N. P., Miyake, A., Corley, R. P., Young, S. E., DeFries, J. C., \& Hewitt, J. K. (2006). Not all executive functions are related to intelligence. Psychological science, 17(2), 172-179.

Gold, B. T., Kim, C., Johnson, N. F., Kryscio, R. J., \& Smith, C. D. (2013). Lifelong bilingualism maintains neural efficiency for cognitive control in aging. Journal of Neuroscience, 33(2), 387-396.

Gray, J. R., \& Thompson, P. M. (2004). Neurobiology of intelligence: science and ethics. Nature Reviews Neuroscience, 5(6), 471-482. 
Green, D. W. (1998). Mental control of the bilingual lexico-semantic system. Bilingualism: Language and cognition, 1(2), 67-81.

Hartanto, A., \& Yang, H. (2016). Disparate bilingual experiences modulate task-switching advantages: A diffusion-model analysis of the effects of interactional context on switch costs. Cognition, 150, 10-19.

Hernández, M., Costa, A., Fuentes, L. J., Vivas, A. B., \& Sebastián-Gallés, N. (2010). The impact of bilingualism on the executive control and orienting networks of attention. Bilingualism: Language and Cognition, 13(3), 315-325.

Hilchey, M. D., \& Klein, R. M. (2011). Are there bilingual advantages on nonlinguistic interference tasks? Implications for the plasticity of executive control processes. Psychonomic bulletin \& review, 18(4), 625-658.

Houtzager, N., Lowie, W., Sprenger, S., \& De Bot, K. (2017). A bilingual advantage in task switching? Age-related differences between German monolinguals and Dutch-Frisian bilinguals. Bilingualism: Language and Cognition, 20(1), 69-79.

Huettig, F., Singh, N., \& Mishra, R. K. (2011). Language-mediated visual orienting behavior in low and high literates. Frontiers in psychology, 2, 285.. 
Incera, S., \& McLennan, C. T. (2018). The time course of within and between-language interference in bilinguals. International Journal of Bilingualism, 22(1), 88-99.

Ivanova, I., Murillo, M., Montoya, R. I., \& Gollan, T. H. (2016). Does bilingual language control decline in older age?. Linguistic approaches to bilingualism, 6(1), 86-118.

Jeffreys, H. (1961). Theory of probability, 3rd edn. Oxford: Oxford University Press

Klein, R. M. (2016). What cognitive processes are likely to be exercised by bilingualism and does this exercise lead to extra-linguistic cognitive benefits?. Linguistic Approaches to Bilingualism, 6(5), 549-564.

Kousaie, S., \& Phillips, N. A. (2017). A behavioural and electrophysiological investigation of the effect of bilingualism on aging and cognitive control. Neuropsychologia, 94, 23-35.

Kroll, J. F., \& Bialystok, E. (2013). Understanding the consequences of bilingualism for language processing and cognition. Journal of Cognitive Psychology, 25(5), 497-514.

Kruschke, J. K. (2011). Bayesian assessment of null values via parameter estimation and model comparison. Perspectives on Psychological Science, 6(3), 299-312.

Kruschke, J. K., \& Liddell, T. M. (2018). Bayesian data analysis for newcomers. Psychonomic bulletin \& review, 25(1), 155-177. 
Kruschke, J. K., Meredith, M., \& Meredith, M. M. (2018). Package 'BEST'.

Lehtonen, M., Soveri, A., Laine, A., Järvenpää, J., de Bruin, A., \& Antfolk, J. (2018). Is bilingualism associated with enhanced executive functioning in adults? A meta-analytic review. Psychological Bulletin, 144(4), 394-425

Luo, L., Luk, G., \& Bialystok, E. (2010). Effect of language proficiency and executive control on verbal fluency performance in bilinguals. Cognition, 114(1), 29-41.

Ma, F., Chen, P., Guo, T., \& Kroll, J. F. (2017). When late second language learners access the meaning of L2 words: Using ERPs to investigate the role of the L1 translation equivalent. Journal of Neurolinguistics, 41, 50-69.

Marian, V., Blumenfeld, H. K., \& Kaushanskaya, M. (2007). The Language Experience and Proficiency Questionnaire (LEAP-Q): Assessing language profiles in bilinguals and multilinguals. Journal of Speech, Language, and Hearing Research, 50(4), 940-967.

McMurray, B., Samelson, V. M., Lee, S. H., \& Tomblin, J. B. (2010). Individual differences in online spoken word recognition: Implications for SLI. Cognitive Psychology, 60(1), 1e39.

Miller, G. A., \& Chapman, J. P. (2001). Misunderstanding analysis of covariance. Journal of abnormal psychology, 110(1), 40. 


\begin{abstract}
Mishra, R. K., Singh, N., Pandey, A., \& Huettig, F. (2012). Spoken language-mediated anticipatory eye-movements are modulated by reading ability-Evidence from Indian low and high literates. Journal of Eye Movement Research, 5(1).
\end{abstract}

Mishra, R. K., Hilchey, M. D., Singh, N., \& Klein, R. M. (2012). On the time course of exogenous cueing effects in bilinguals: higher proficiency in a second language is associated with more rapid endogenous disengagement. The Quarterly journal of experimental psychology, 65(8), 1502-1510.

Mishra, R. K., \& Singh, N. (2016). The influence of second language proficiency on bilingual parallel language activation in Hindi-English bilinguals. Journal of Cognitive Psychology, 28(4), 396-411.

Mukadam, N., Sommerlad, A., \& Livingston, G. (2017). The relationship of bilingualism compared to monolingualism to the risk of cognitive decline or dementia: a systematic review and meta-analysis. Journal of Alzheimer's Disease, (Preprint), 1-10.

Nag, S. (2011). The akshara languages: what do they tell us about children's literacy learning?. Language-cognition: state of the art, 291-310.

Olivers, C. N. L., Huettig, F., Singh, J. P., \& Mishra, R. K. (2014). The influence of literacy on visual search. Visual Cognition, 22(1), 74-101. 
Paap, K. R., \& Greenberg, Z. I. (2013). There is no coherent evidence for a bilingual advantage in executive processing. Cognitive psychology, 66(2), 232-258.

Paap, K. R., Johnson, H. A., \& Sawi, O. (2014). Are bilingual advantages dependent upon specific tasks or specific bilingual experiences?. Journal of Cognitive Psychology, 26(6), 615639.

Paap, K. R., Johnson, H. A., \& Sawi, O. (2015). Bilingual advantages in executive functioning either do not exist or are restricted to very specific and undetermined circumstances. Cortex, 69, 265-278.

Papageorgiou, A., Bright, P., Periche Tomas, E., \& Filippi, R. (2018). Author accepted manuscript: Evidence against a cognitive advantage in the older bilingual population. Quarterly Journal of Experimental Psychology, 1747021818796475.

Pelham, S. D., \& Abrams, L. (2014). Cognitive advantages and disadvantages in early and late bilinguals. Journal of Experimental Psychology: Learning, Memory, and Cognition, 40(2), 313.

Prior, A., \& MacWhinney, B. (2010). A bilingual advantage in task switching. Bilingualism: Language and cognition, 13(2), 253-262.. 
Qu, L., Low, J. J. W., Zhang, T., Li, H., \& Zelazo, P. D. (2016). Bilingual advantage in executive control when task demands are considered. Bilingualism: Language and Cognition, 19(2), 277-293.

Ramos, S., García, Y. F., Antón, E., Casaponsa, A., \& Duñabeitia, J. A. (2017). Does learning a language in the elderly enhance switching ability?. Journal of Neurolinguistics, 43, 39-48.

Raven, J. C. (1958). Standard Progressive Matrices. London: Lewis

Rouder, J. N., Speckman, P. L., Sun, D., Morey, R. D., \& Iverson, G. (2009). Bayesian t tests for accepting and rejecting the null hypothesis. Psychonomic bulletin \& review, 16(2), 225237

Roychoudhuri, K. S., Prasad, S. G., \& Mishra, R. K. (2016). Iconic Native Culture Cues Inhibit Second Language Production in a Non-immigrant Population: Evidence from BengaliEnglish Bilinguals. Frontiers in Psychology, 7(October), 1-8.

Saint-Aubin, J., Hilchey, M. D., Mishra, R., Singh, N., Savoie, D., Guitard, D., \& Klein, R. M. (2018). Does the relation between the control of attention and second language proficiency generalize from India to Canada?. Canadian Journal of Experimental Psychology/Revue canadienne de psychologie expérimentale, 72(3), 208. 
Singh, N., \& Mishra, R. K. (2012). Does language proficiency modulate oculomotor control? Evidence from Hindi-English bilinguals. Bilingualism: Language and Cognition, 15(4), 771781.

Singh, N., \& Mishra, R. K. (2013). Second language proficiency modulates conflictmonitoring in an oculomotor Stroop task: evidence from Hindi-English bilinguals. Frontiers in psychology, 4, 322 .

Singh, N., \& Mishra, R. K. (2015). The modulatory role of second language proficiency on performance monitoring: evidence from a saccadic countermanding task in high and low proficient bilinguals. Frontiers in psychology, 5, 1481.

Singh, J. P., \& Mishra, R. K. (2016). Effect of bilingualism on anticipatory oculomotor control. International Journal of Bilingualism, 20(5), 550-562.

Struys, E., Duyck, W., \& Woumans, E. A. (2018). The role of cognitive development and strategic task tendencies in the bilingual advantage controversy. Frontiers in psychology, 9, 1790 .

Tao, L., Marzecová, A., Taft, M., Asanowicz, D., \& Wodniecka, Z. (2011). The efficiency of attentional networks in early and late bilinguals: the role of age of acquisition. Frontiers in psychology, 2, 123. 
Tse, C. S., \& Altarriba, J. (2012). The effects of first-and second-language proficiency on conflict resolution and goal maintenance in bilinguals: Evidence from reaction time distributional analyses in a Stroop task. Bilingualism: Language and Cognition, 15(3), 663676.

Valian, V. (2015). Bilingualism and cognition. Bilingualism: Language and Cognition, 18(1), $3-24$.

Von Bastian, C. C., Souza, A. S., \& Gade, M. (2016). No evidence for bilingual cognitive advantages: A test of four hypotheses. Journal of Experimental Psychology: General, 145(2), 246.

Wetzels, R., Matzke, D., Lee, M. D., Rouder, J. N., Iverson, G. J., \& Wagenmakers, E. J. (2011). Statistical evidence in experimental psychology: An empirical comparison using $855 \mathrm{t}$ tests. Perspectives on Psychological Science, 6(3), 291-298.

Wilson, C. M., Christensen, B. K., King, J. P., Li, Q., \& Zelazo, P. D. (2008). Decomposing perseverative errors among undergraduates scoring high on the Schizotypal Personality Questionnaire. Schizophrenia Research, 106(1), 3-12.

Woods et al. (2011). Improving digit span assessment of short-term verbal memory. Journal of Clinical and Experimental Neuropsychology, 33, 101-111 
Woumans, E., Santens, P., Sieben, A., Versijpt, J. A. N., Stevens, M., \& Duyck, W. (2015).

Bilingualism delays clinical manifestation of Alzheimer's disease. Bilingualism: Language and Cognition, 18(3), 568-574.

Yang, H., Hartanto, A., \& Yang, S. (2016). The importance of bilingual experience in assessing bilingual advantages in executive functions. Cortex, 75, 237.

Yang, H., Hartanto, A., \& Yang, S. (2017). Bilingualism confers advantages in task switching: Evidence from the dimensional change card sort task. Bilingualism: Language and Cognition, 1-19.

Appendix A. Descriptive statistics of all the tasks.

\begin{tabular}{lll}
\hline Task & High proficient bilinguals & Low proficient bilinguals
\end{tabular}

\begin{tabular}{lllll}
\hline & Mean & SD & Mean & SD \\
\hline Numerical Stroop & & & & \\
\hline Congruent & 627.24 & $(134.14)$ & 613.02 & $(139.1)$ \\
Incongruent & 632.06 & $(114.74)$ & 616.86 & $(129.82)$ \\
Stroop Effect & 4.83 & $(46.21)$ & 3.83 & $(53.16)$ \\
\hline Attentional Network Task (ANT) & & & & \\
\hline Executive Network & 754.26 & $(104.01)$ & 754.81 & $(80.76)$ \\
\hline Congruent & 752.3 & $(126.45)$ & 759 & $(86)$ \\
Neutral & 877.99 & $(125.95)$ & 883.90 & $(97.00)$ \\
\hline Incongruent & & & & \\
\hline
\end{tabular}


Conflict Effect

$123.74 \quad(74.63)$

129.09

$(55.53)$

Alerting Network

\begin{tabular}{lcccc}
\hline No Cue & 806.26 & $(125.10)$ & 804.35 & $(86.92)$ \\
Double Cue & 796.13 & $(133.96)$ & 789.62 & $(83.20)$ \\
Alerting Effect & 10.13 & $(36.37)$ & 14.73 & $(36.91)$ \\
\cline { 1 - 2 } Orienting Network & & & & \\
\cline { 1 - 3 } Central Cue & 787.36 & $(121.12)$ & 795.34 & $(82.63)$ \\
Spatial Cue & 779.69 & $(103.20)$ & 797.73 & $(97.88)$ \\
Orienting Effect & 7.67 & $(32.30)$ & -2.39 & $(41.11)$
\end{tabular}

Stop-signal task

Stop Signal Reaction Time(SSRT) $467.63 \quad(142.20)$

492.54

(213.31)

\section{Dimensional Change Card Sort}

(DCCS) task

Colour Task

Local Switch Cost

0.85

$(0.59)$

1.02

$(0.39)$

Global Switch Cost

0.31

$(0.25)$

0.33

$(0.23)$

Shape Task

Local Switch Cost

0.89

$(0.41)$

0.95

Global Switch Cost

$0.48 \quad(0.28)$

0.44

$(0.32)$

The correlation tables for all the tasks are listed below. Only the values in the last column change substantially for each task.

\section{Appendix B. Correlational analysis for ANT}

\begin{tabular}{lllllllllll}
\hline & 2. & 3. & 4. & 5. & 6. & 7. & 8. & 9. & 10. & 11. \\
\hline 1. Gender & $\mathbf{0 . 3 7 ^ { * }}$ & 0.23 & 0.2 & -0.13 & 0.1 & 0.06 & $\mathbf{0 . 3}^{*}$ & -0.1 & 0.2 & -0.03 \\
\hline 2. Age & & 0.005 & 0.05 & 0.05 & -0.07 & -0.06 & $\mathbf{0 . 8}^{\text {****}}$ & -0.17 & -0.05 & -0.11 \\
\hline 3. MMSE & & & $\mathbf{0 . 3 6}$ & 0.13 & 0.19 & $\mathbf{0 . 3 4}$ & 0.1 & 0.06 & 0.1 & 0.04 \\
\hline
\end{tabular}




\begin{tabular}{|c|c|c|c|c|c|c|}
\hline 4. IQ & 0.19 & $0.34^{*}$ & 0.09 & 0.11 & -0.03 & -0.12 \\
\hline 5. SES & 0.19 & 0.1 & -0.09 & -0.15 & 0.08 & -0.13 \\
\hline 6. L2 proficiency ${ }^{\mathrm{a}}$ & & 0.08 & 0.10 & -0.07 & $0.3^{*}$ & -0.07 \\
\hline 7. L2 exposure ${ }^{b}$ & & & -0.05 & $0.35^{*}$ & $0.4^{* *}$ & -0.24 \\
\hline 8. $\mathrm{YOB}^{\mathrm{c}}$ & & & & $-0.29 *$ & -0.03 & 0.04 \\
\hline 9. Alerting effect & & & & & 0.18 & -0.07 \\
\hline 10. Orienting effect & & & & & & $-0.4^{* *}$ \\
\hline
\end{tabular}

11. Conflict effect

Note: ${ }^{* * *} p<0.001,{ }^{* *} p<0.01,{ }^{*} p<0.05,{ }^{*} p<0.1$

${ }^{\text {aL2 }}$ proficiency refers to the cumulative L2 proficiency score used to divide the participants into two groups

${ }^{b} \mathrm{~L} 2$ exposure refers to the percentage of exposure to L2 extracted from the questionnaire as an answer to the question: "Please list what percentage of the time you are currently, on average, exposed to each language. (Your percentages should add up to $100 \%$ )")

${ }^{\mathrm{C} Y O B}$ : Years of Bilingualism $=$ Current age - AoA of L2

\section{Appendix C. Correlational analysis for Numerical Stroop task}

\begin{tabular}{lllllllll}
\hline & 2. & 3. & 4. & 5. & 6. & 7. & 8. & 9. \\
\hline 1. Gender & $\mathbf{0 . 3 4}$ & 0.22 & 0.2 & -0.14 & 0.12 & 0.06 & $\mathbf{0 . 3}^{*}$ & 0.07 \\
\hline 2. Age & & 0.002 & 0.05 & 0.06 & -0.04 & -0.07 & $\mathbf{0 . 8}^{\text {*** }}$ & 0.16 \\
\hline 3. MMSE & & & $\mathbf{0 . 3 7 ^ { * }}$ & 0.11 & 0.19 & $\mathbf{0 . 3 5}^{*}$ & 0.09 & $\mathbf{- 0 . 3 3}^{*}$ \\
\hline 4. IQ & & & & 0.13 & $\mathbf{0 . 3 2}^{*}$ & $\mathbf{0 . 3 6}$ & 0.11 & -0.08 \\
\hline 5. SES & & & & 0.12 & 0.06 & -0.11 & -0.03 \\
\hline 6. L2 proficiency & & & & & 0.11 & 0.14 & 0.13 \\
\hline 7. L2 exposure & & & & & & -0.04 & -0.23 \\
\hline 8. YOB & & & & & & & 0.13 \\
\hline 9. Stroop
\end{tabular}

9. Stroop effect

Note: ${ }^{* * *} p<0.001,{ }^{* *} p<0.01,{ }^{*} p<0.05,{ }^{\sharp} p<0.1$

\section{Appendix D. Correlational analysis for DCCS task}

\begin{tabular}{llllllllllll}
\hline & 2. & 3. & 4. & 5. & 6. & 7. & 8. & 9. & 10. & 11. & 12. \\
\hline 1. Gender & $\mathbf{0 . 3 4}^{*}$ & 0.22 & 0.2 & -0.14 & 0.12 & 0.06 & $\mathbf{0 . 3}$ & -0.08 & -0.15 & -0.15 & -0.004 \\
\hline 2. Age & & 0.002 & 0.05 & 0.06 & -0.04 & -0.07 & $\mathbf{0 . 8}^{* * *}$ & 0.02 & 0.04 & -0.09 & -0.02 \\
\hline 3. MMSE & & & $\mathbf{0 . 3 7 ^ { * }}$ & 0.11 & 0.19 & $\mathbf{0 . 3 5}^{*}$ & 0.09 & -0.07 & $\mathbf{- 0 . 2 4}^{\#}$ & $\mathbf{- 0 . 4}^{* *}$ & - \\
\hline
\end{tabular}


$0.39^{* * *}$

\begin{tabular}{llllllll}
\hline 4. IQ & 0.13 & $\mathbf{0 . 3 2}^{*}$ & $\mathbf{0 . 3 6}^{*}$ & 0.11 & -0.11 & -0.18 & $\mathbf{- 0 . 3 6}$
\end{tabular}

\begin{tabular}{llllllll}
\hline 5. SES & 0.12 & 0.06 & -0.11 & -0.02 & -0.04 & -0.04 & -0.21 \\
\hline 6. L2 proficiency & & 0.11 & 0.14 & 0.03 & -0.09 & 0.04 & -0.02 \\
\hline 7. L2 exposure & & & -0.04 & -0.18 & $-\mathbf{- 0 . 2 6}^{\#}$ & 0.2 & 0.09 \\
\hline 8. YOB & & & -0.05 & -0.12 & -0.12 & 0.02 \\
\hline 9. Global SC (shape) & & & & & $\mathbf{0 . 6 6}^{\text {*** }}$ & $\mathbf{0 . 3 2}^{*}$ & 0.23
\end{tabular}

\begin{tabular}{|c|c|c|}
\hline 10. Local SC (shape) ${ }^{\mathbf{a}}$ & $0.34^{*}$ & $0.29^{*}$ \\
\hline 11. Global SC (colour) & & $0.82^{* *}$ \\
\hline
\end{tabular}

12. Local SC (colour) ${ }^{\mathbf{b}}$

Note: ${ }^{* * *} p<0.001,{ }^{* *} p<0.01,{ }^{*} p<0.05,{ }^{\#} p<0.1$

aShape-dominant block, ${ }^{\mathbf{b}}$ Colour-dominant block

\section{Appendix E. Correlational analysis for Stop-signal task}

\begin{tabular}{|c|c|c|c|c|c|c|c|c|}
\hline & 2. & 3. & 4. & 5. & 6. & 7. & 8. & 9. \\
\hline 1. Gender & $0.34^{*}$ & 0.22 & 0.2 & -0.14 & 0.12 & 0.06 & $0.3^{*}$ & 0.02 \\
\hline 2. Age & & 0.002 & 0.05 & 0.06 & -0.04 & -0.07 & $0.8^{* * * *}$ & -0.22 \\
\hline 3. MMSE & & & $0.37^{*}$ & 0.11 & 0.19 & $0.35^{*}$ & 0.09 & 0.01 \\
\hline 4. IQ & & & & 0.13 & $0.32^{*}$ & $0.36^{*}$ & 0.11 & -0.09 \\
\hline 5. SES & & & & & 0.12 & 0.06 & -0.11 & 0.03 \\
\hline 6. L2 proficiency & & & & & & 0.11 & 0.14 & 0.02 \\
\hline 7. L2 exposure & & & & & & & -0.04 & -0.07 \\
\hline 8. YOB & & & & & & & & -0.16 \\
\hline 9. $\mathrm{SSRT}^{\mathrm{a}}$ & & & & & & & & \\
\hline
\end{tabular}

Note: ${ }^{* * *} p<0.001,{ }^{* *} p<0.01,{ }^{*} p<0.05,{ }^{\#} p<0.1$

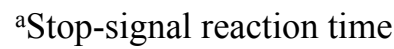

\section{Appendix F. ANCOVA results}

Results from analysis of co-variance with cumulative L2 proficiency as the covariate. 


$F \quad p \quad \eta^{2} \quad$ Group means (in ms)

\begin{tabular}{|c|c|c|c|c|}
\hline \multicolumn{5}{|c|}{ ANT alerting effect } \\
\hline Exposure to L2 & 1.13 & 0.29 & 0.02 & $\begin{array}{l}\mathrm{HE}: \mathrm{M}=16.84, \mathrm{SD}=43.3 \\
\mathrm{LE}: \mathrm{M}=8.3, \mathrm{SD}=28.4\end{array}$ \\
\hline L2 proficiency & 0.71 & 0.4 & 0.02 & \\
\hline \multicolumn{5}{|c|}{ ANT orienting effect } \\
\hline Exposure to L2 & 4 & $0.05^{\#}$ & 0.08 & $\begin{array}{l}H E: M=16.4, S D=32.4 \\
L E: M=-10.7, S D=36.9\end{array}$ \\
\hline L2 proficiency & 1.5 & 0.2 & 0.03 & \\
\hline \multicolumn{5}{|c|}{ ANT conflict effect } \\
\hline Exposure to L2 & 0.81 & 0.37 & 0.02 & $\begin{array}{l}\mathrm{HE}: \mathrm{M}=116.5, \mathrm{SD}=41.6 \\
\mathrm{LE}: \mathrm{M}=136.1, \mathrm{SD}=81.1\end{array}$ \\
\hline L2 proficiency & 0.01 & 0.9 & $<0.001$ & \\
\hline \multicolumn{5}{|l|}{ Stroop effect } \\
\hline Exposure to L2 & 6.1 & $0.02^{*}$ & 0.1 & $\begin{array}{l}\mathrm{HE}: M=-7.9, \mathrm{SD}=43.8 \\
\mathrm{LE}: \mathrm{M}=16.5, \mathrm{SD}=52.3\end{array}$ \\
\hline L2 proficiency & 3.72 & $0.06^{\#}$ & 0.06 & \\
\hline \multicolumn{5}{|c|}{ Global SC (shape) } \\
\hline Exposure to L2 & 0.54 & 0.47 & 0.01 & $\begin{array}{l}\mathrm{HE}: \mathrm{M}=0.5, \mathrm{SD}=0.27 \\
\mathrm{LE}: \mathrm{M}=0.43, \mathrm{SD}=0.33\end{array}$ \\
\hline L2 proficiency & 0.006 & 0.94 & $<0.001$ & \\
\hline \multicolumn{5}{|l|}{ Local SC (shape) } \\
\hline Exposure to L2 & 0.00004 & 0.9 & $<0.001$ & $\begin{array}{l}\text { HE: } M=0.92, S D=0.4 \\
\text { LE: } M=0.93, S D=0.5\end{array}$ \\
\hline L2 proficiency & 0.02 & 0.89 & $<0.001$ & \\
\hline \multicolumn{5}{|c|}{ Global SC (colour) } \\
\hline Exposure to L2 & 1.15 & 0.29 & 0.02 & $\begin{array}{l}\mathrm{HE}: \mathrm{M}=0.29, \mathrm{SD}=0.28 \\
\mathrm{LE}: \mathrm{M}=0.35, \mathrm{SD}=0.2\end{array}$ \\
\hline L2 proficiency & 0.42 & 0.52 & 0.009 & \\
\hline \multicolumn{5}{|c|}{ Local SC (colour) } \\
\hline Exposure to L2 & 1.2 & 0.27 & 0.02 & $\begin{array}{l}\mathrm{HE}: \mathrm{M}=0.85, \mathrm{SD}=0.57 \\
\mathrm{LE}: \mathrm{M}=1.02, \mathrm{SD}=0.4\end{array}$ \\
\hline L2 proficiency & 0.01 & 0.92 & $<0.001$ & \\
\hline SSRT & & & & \\
\hline
\end{tabular}




\begin{tabular}{lllll} 
Exposure to L2 & 0.26 & 0.6 & 0.006 & $\begin{array}{l}\text { HE: } M=469.2, S D=136.3 \\
\text { LE: } M=491, S D=217.3\end{array}$ \\
\hline L2 proficiency & 0.1 & 0.76 & 0.002 &
\end{tabular}

${ }^{\mathrm{a}}$ Group means obtained from ANCOVA after controlling for L2 proficiency scores.

HE: high exposure, LE: low exposure

Table 1: Demographic data of participants

\begin{tabular}{lllll}
\hline & \multicolumn{2}{l}{ High-proficiency bilinguals } & \multicolumn{2}{l}{ Low-proficiency bilinguals } \\
& $(\boldsymbol{n}=\mathbf{2 5})$ & & $(\boldsymbol{n}=\mathbf{2 5})$ & \\
\hline & Mean & SD & Mean & SD \\
\hline Age (in years) & 57.44 & 4.32 & 56.9 & 3.98 \\
\hline Age of Acquisition (in & & & & \\
years) of: & & & \\
L1 & 2.20 & 1.41 & 1.62 & 0.90 \\
L2 & 9.04 & 2.84 & 9.88 & 2.98 \\
\hline
\end{tabular}




\begin{tabular}{|c|c|c|c|c|}
\hline \multicolumn{5}{|c|}{ Number of years of formal } \\
\hline \multicolumn{5}{|l|}{ education in: } \\
\hline $\mathrm{L} 1$ & 8.32 & 4.63 & 10.1 & 3.89 \\
\hline $\mathrm{L} 2$ & 3.28 & 4.31 & 1.92 & 3.89 \\
\hline \multicolumn{5}{|l|}{ Percentage exposure to ${ }^{\mathrm{a}}$ : } \\
\hline L1 & 66.16 & 18.48 & $75.52^{\#}$ & 18.68 \\
\hline $\mathrm{L} 2$ & 26.32 & 16.09 & 20.1 & 18.07 \\
\hline \multicolumn{5}{|c|}{ Self-reported proficiency } \\
\hline \multicolumn{5}{|l|}{ score of L1 in: } \\
\hline Reading $\mathbf{b}$ & 9.44 & 0.768 & 9.40 & 1.04 \\
\hline Speaking ${ }^{\mathbf{b}}$ & 9.12 & 0.917 & 9.10 & 1.10 \\
\hline Understanding spoken & 9.48 & 0.714 & 9.16 & 1.21 \\
\hline \multicolumn{5}{|l|}{ language $\mathbf{b}^{\mathbf{b}}$} \\
\hline \multicolumn{5}{|c|}{ Self-reported proficiency } \\
\hline \multicolumn{5}{|l|}{ score of L2 in: } \\
\hline Readingb $^{\mathbf{b}}$ & 8.92 & 0.909 & $7.68^{*}$ & 1.49 \\
\hline Speaking ${ }^{\mathbf{b}}$ & 8.04 & 1.37 & $6.16^{*}$ & 1.68 \\
\hline Understanding spoken & 8.68 & 1.11 & $7.16^{*}$ & 1.68 \\
\hline \multicolumn{5}{|l|}{ language $^{\mathbf{b}}$} \\
\hline \multicolumn{5}{|c|}{ Naming latency (in ms) in: } \\
\hline L1 & 1142.45 & 237.45 & 1202.17 & 229.04 \\
\hline $\mathrm{L} 2$ & 1156.82 & 201.95 & 1172.39 & 220.56 \\
\hline
\end{tabular}

Semantic fluency score in: 


\begin{tabular}{lcccc} 
L1 & 13.48 & 3.94 & $11.4^{*}$ & 2.82 \\
L2 & 11.38 & 2.91 & $7.58^{*}$ & 2.72 \\
\hline L2 vocabulary test score & 54.52 & 15.48 & $33.44^{*}$ & 17.46
\end{tabular}

\begin{tabular}{lllll}
\hline Composite scorec: & & & & \\
L1 & 0.000713 & 0.00832 & -0.000712 & 0.0071 \\
L2 & 0.0471 & 0.00538 & $0.0271^{*}$ & 0.01063 \\
\hline Current switching & 4.48 & 1.58 & 4.20 & 1.98 \\
frequency & & & & \\
\end{tabular}

\begin{tabular}{lllll}
\hline $\begin{array}{l}\text { Preferred switching } \\
\text { frequency with a balanced }\end{array}$ & 3.96 & 1.95 & 3.04 & 1.84 \\
$\begin{array}{l}\text { bilingual } \\
\text { MMSE }\end{array}$ & & & & \\
\hline Non-verbal IQ & 28.92 & 1.52534 & 28.72 & 1.27541 \\
\hline Working memory & 36.0417 & 7.04322 & $30.4167^{\#}$ & 7.45955 \\
Forward digit span task & $6.43(n=23)$ & 0.945 & $5.91(n=22)$ & 1.41 \\
Backward digit span task & $5.87(n=23)$ & 1.058 & $5.18(n=22)$ & 1.37 \\
\hline SES & & & & \\
\hline
\end{tabular}

${ }^{*} p<0.001,{ }^{*} p<0.05$

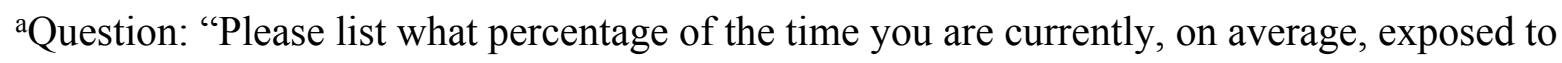
each language. (Your percentages should add up to 100\%)"

${ }^{\mathrm{b}}$ Self-rating of language proficiency by each participant on a scale of 1 to 10 (10 being the highest). 
${ }^{\mathrm{c}}$ Composite scores for L1 and L2 consisted of scores from object naming test, semantic fluency test, self-ratings on proficiency and vocabulary test (only for L2 score).

${ }^{\mathrm{d}}$ Question: "How often are you in a situation when you switch between the languages Telugu and English?” - 1 (never) to 7 (very often).

${ }^{\mathrm{e}}$ Question: "When choosing a language to speak with a person who is equally fluent in all your languages, how often would you switch between languages?" - 1 (never) to 7 (very often).

${ }^{\dagger}$ As shorter naming latencies reflects higher language proficiency, naming latencies were multiplied by -1 so that a larger resulting value corresponded with higher composite L 2 score (Ma, Chen, Guo, \& Kroll, 2017).

\section{Figure captions}

Figure 1. A representative sample of studies conducted to examine bilingual advantage in the elderly population since 2004. Blue circles indicate studies on healthy older adults measuring performance on cognitive tasks and red circles indicate studies that have examined the role of bilingualism in the onset of a neurological disease based on patient records. The double circles indicate studies that have treated bilingualism as a continuous variable and tested bilinguals based on their second language proficiency.

Figure 2. Comparison of ANT (A), Alerting effect (B), Orienting effect (C) conflict effect across L2 proficiency groups. (D) Group comparison of Stroop effect from numerical Stroop task. (E) Local switch cost and Global switch cost comparison of DCCS task for Colour and 
Shape dominant blocks across L2 proficiency groups. (F) Comparison of Stop-signal Reaction Time(SSRT) across L2 proficiency groups.

Note: Error bars indicate $+1 \mathrm{SE}$

Figure 3. The posterior distributions of the difference in group means for all the tasks. The y axis is the probability density and the $\mathrm{x}$ axis is the parameter value (difference in group means in $\mathrm{ms}$ ). The ROPE limits are marked by red vertical lines. The criteria for setting the ROPE limits for each task are described in the text.

Note: $\mu_{1}$ : high proficient group, $\mu_{2}$ : low proficient group 


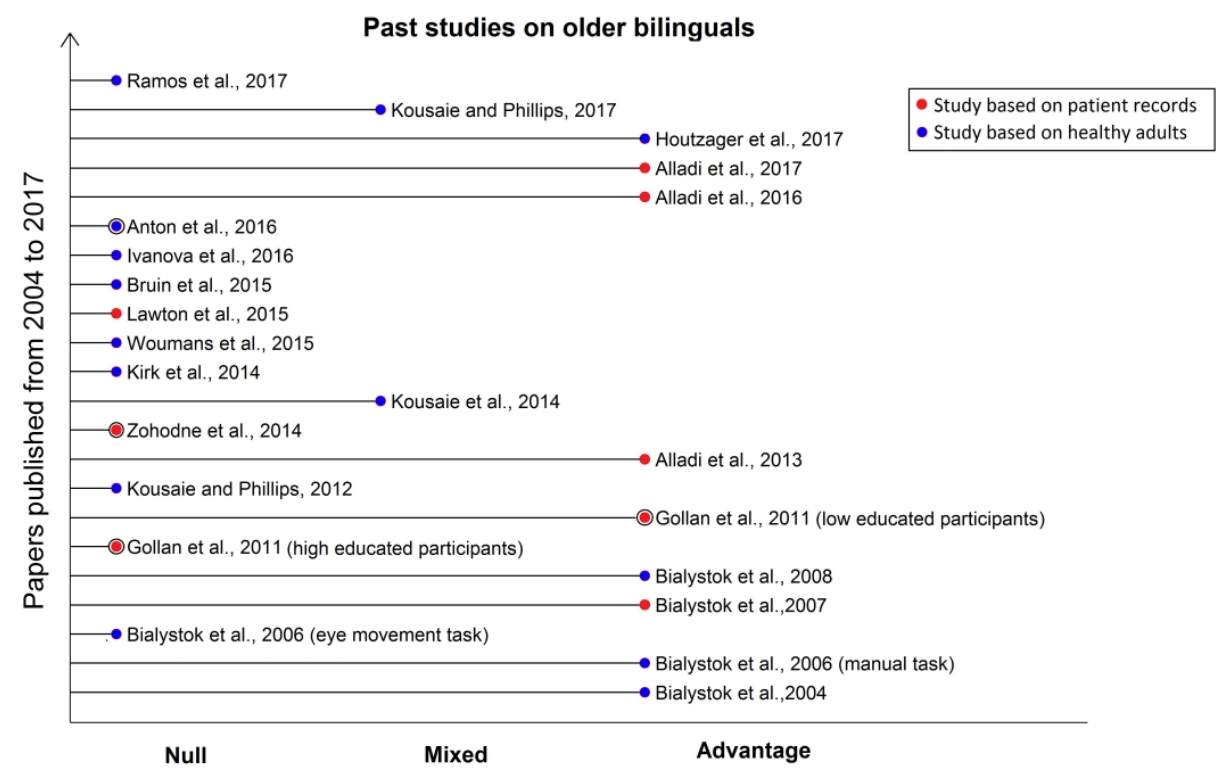

A representative sample of studies conducted to examine bilingual advantage in the elderly population since 2004. Blue circles indicate studies on healthy older adults measuring performance on cognitive tasks and red circles indicate studies that have examined the role of bilingualism in the onset of a neurological disease based on patient records. The double circles indicate studies that have treated bilingualism as a continuous variable and tested bilinguals based on their second language proficiency.

$1272 \times 781 \mathrm{~mm}(96 \times 96 \mathrm{DPI})$ 

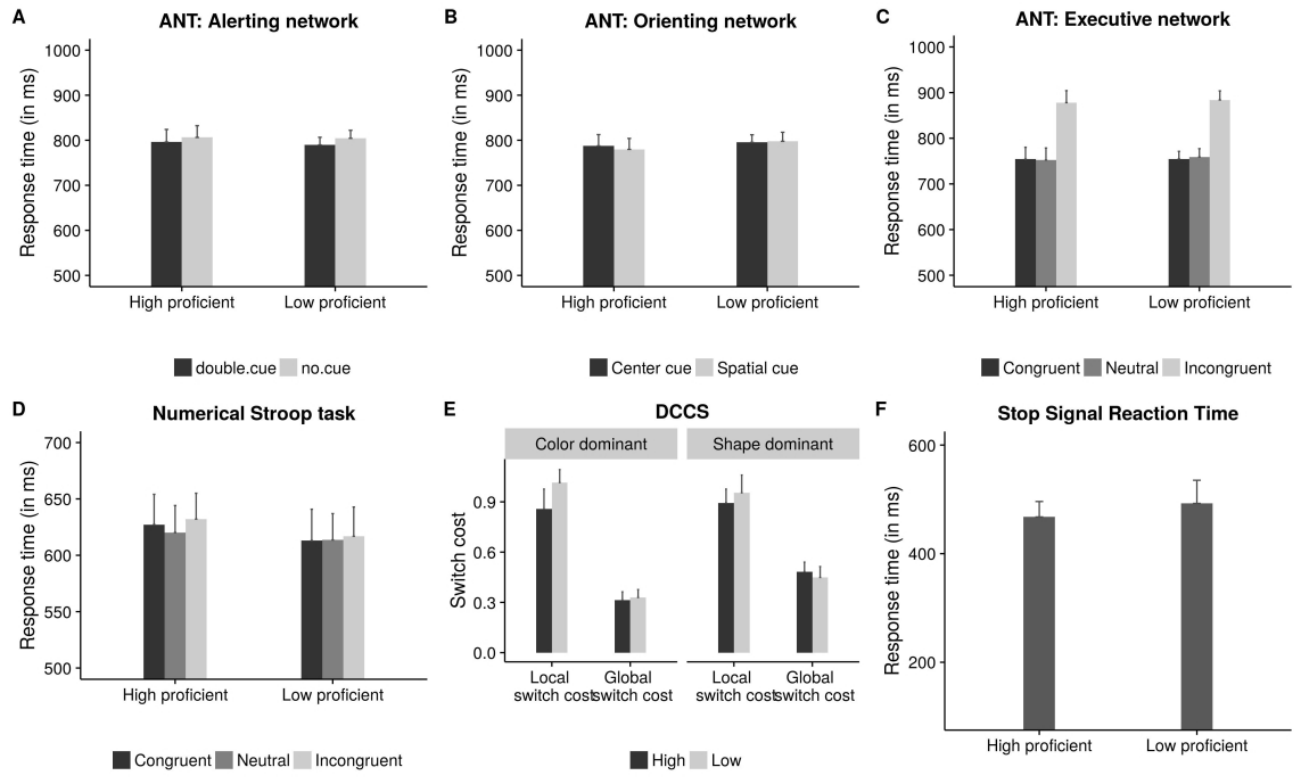

Figure 2. Comparison of ANT (A), Alerting effect (B), Orienting effect (C) conflict effect across L2 proficiency groups. (D) Group comparison of stroop effect from numerical stroop task. (E) Local switch cost and Global switch cost comparison of DCCS for Colour and Shape dominant tasks across L2 proficiency groups. (F) Comparison of Stop-signal Reaction Time(SSRT) across L2 proficiency groups. Note: Error bars indicate $+1 \mathrm{SE}$ $335 \times 203 \mathrm{~mm}(300 \times 300$ DPI $)$ 

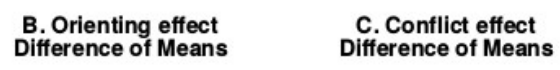

G. DCCS Local SC (colour) Difference of Means

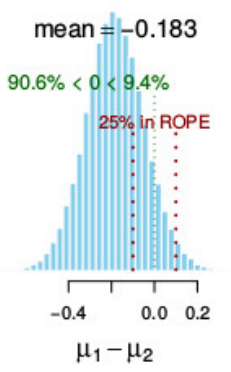

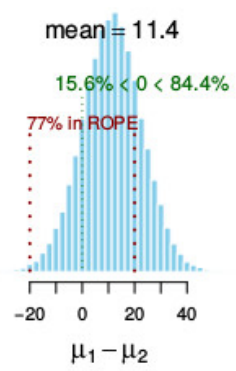



$$
\mu_{1}-\mu_{2}
$$

DCCS Global SC (colour) Difference of Means

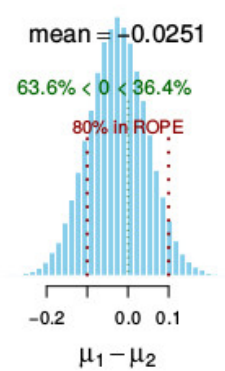
E. DCCS Local SC (shape)
Difference of Means

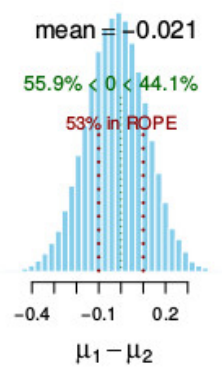

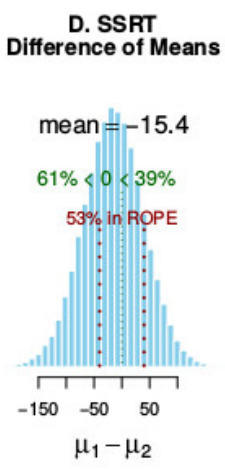

F. DCCS Global SC (shape) Difference of Means



Figure 3. The posterior distributions of the difference in group means for all the tasks. The y axis is the probability density and the $x$ axis is the parameter value (difference in group means in ms). The ROPE limits are marked by red vertical lines. The criteria for setting the ROPE limits for each task are described in the text.

Note: $\mu 1$ : high proficient group, $\mu 2$ : low proficient group

$$
203 \times 152 \mathrm{~mm}(100 \times 100 \mathrm{DPI})
$$

